Research Article

\title{
Wind Load and Structural Parameters Estimation from Incomplete Measurements
}

\author{
Huili Xue, Hongjun Liu (D, Huayi Peng, Yin Luo, and Kun Lin (D) \\ Department of Civil and Environmental Engineering, Harbin Institute of Technology, Shenzhen 518055, China \\ Correspondence should be addressed to Kun Lin; linkun@hit.edu.cn
}

Received 5 December 2018; Revised 28 February 2019; Accepted 20 March 2019; Published 17 April 2019

Academic Editor: Stefano Manzoni

Copyright (c) 2019 Huili Xue et al. This is an open access article distributed under the Creative Commons Attribution License, which permits unrestricted use, distribution, and reproduction in any medium, provided the original work is properly cited.

\begin{abstract}
The extended minimum variance unbiased estimation approach can be used for joint state/parameter/input estimation based on the measured structural responses. However, it is necessary to measure the structural displacement and acceleration responses at each story for the simultaneous identification of structural parameters and unknown wind load. A novel method of identifying structural state, parameters, and unknown wind load from incomplete measurements is proposed. The estimation is performed in a modal extended minimum variance unbiased manner, based on incomplete measurements of wind-induced structural displacement and acceleration responses. The feasibility and accuracy of the proposed method are numerically validated by identifying the wind load and structural parameters on a ten-story shear building structure with incomplete measurements. The effects of crucial factors, including sampling duration and the number of measurements, are discussed. Furthermore, the practical application of the developed inverse method is evaluated based on wind tunnel testing results of a $234 \mathrm{~m}$ tall building structure. The results indicate that the structural state, parameters, and unknown wind load can be identified accurately using the proposed approach.
\end{abstract}

\section{Introduction}

Wind load is one of the main loads during the design stage of tall buildings $[1,2]$. Studies show that the wind load on a tall building varies depending on the terrain condition, the shape of the building, and the surrounding buildings [3]. In most design processes, wind load is calculated according to the design code $[4,5]$. However, it is difficult to calculate the time histories of wind load based on design code as the wind load design code is determined based on statistical information. Wind tunnel tests and computational fluid dynamic simulations are currently used to determine the timevarying wind load on a given structure $[6,7]$. However, neither of the methods can exactly reproduce the incident turbulence and the characteristic of the surrounding buildings. Field measurement is regarded as the most accurate way of obtaining the time-varying wind load on tall buildings. However, due to the limitation of the wind load measurement technique, real-time measurement of wind load is difficult by field measurement. Compared to wind load measurement, the measurement of wind-induced displacement and acceleration responses is easier to achieve and more accurate.

In recent years, a lot of force estimation methods have been developed [8-10]. Law et al. identified wind load on a $50 \mathrm{~m}$ guyed mast from structural responses by regularization of the identification equation [11]. Lu and Law proposed a method for identifying unknown load using sensitivity measures of the dynamic response with respect to the input load [12]. Liu and Shepard developed a dynamic force identification approach based on the enhanced least squares approach in the frequency domain [13]. Ma et al. presented a Kalman filter method with a recursive estimator to determine the unknown excitation $[14,15]$. The aforementioned approaches require that the unknown load has been generally point load acting at a specific DOF. However, wind loads acting on a building structure vary with space and time, and the methods in previous works 
cannot directly be used for wind load identification of building structures.

To address the aforementioned issue, Hwang et al. proposed the Kalman filtering approach in modal domain to estimate modal loads on a structure using limited measured response $[16,17]$. Zhi et al. developed the Kalman filtering method and proper orthogonal decomposition technique to estimate the modal wind load on tall buildings [18, 19]. In 2007, Gillijns and Moor proposed an approach for joint input-state estimation in discrete-time dynamic system based on minimum variance unbiased solution [20]. Lourens et al. applied the method to estimate structural responses and unknown inputs in both numerical and experimental studies [21]. This method requires no assumption or prior knowledge about the unknown inputs, and it can be used for wind load identification in the physical domain [22]. Unfortunately, the aforementioned wind load estimation approaches assumed that the structural parameters are known a priori. However, for actual building structures, the structural parameters are generally determined based on the finite element model and it is difficult to calculate structural parameters exactly due to the material aging and damage in the structures.

To solve this problem, Wan et al. proposed a method called EGDF which is an extension of the unbiased minimum variance estimation for coupled state/input/parameter identification for nonlinear systems in state space [23]. Song developed the joint input-state estimation technique for joint input-state-parameter estimation based on the unscented minimum variance unbiased (UMVU) estimation method [24]. However, both EGDF and UMVU methods require that it is necessary to measure the acceleration responses at the locations where unknown inputs are applied, i.e., complete acceleration measurements at all DOFs are requested for simultaneous estimation of wind load and unknown structural parameters.

A novel method of the modal extended unbiased minimum variance estimation for joint state/parameter/wind load estimation from incomplete measurements is proposed in this study. The proposed method is able to simultaneously estimate the wind loads and structural parameters without using complete acceleration measurements. Moreover, the data fusion of acceleration responses and interstory displacement responses is used to prevent the drifts of the identified displacements responses and wind loads. The content of this paper is organized as follows. In Section 2, the proposed method of the modal extended unbiased minimum variance estimator is derived and the necessary mathematical proofs are given. In Section 3, a numerical validation by identifying wind loads and structural parameters from incomplete measurements on a ten-story shear building structure is addressed. Moreover, the effects of key factors, including sampling duration and the number of measurements, are discussed. In Section 4, a synchronous multipressure scanning system wind tunnel test on a $234 \mathrm{~m}$ tall building structure is carried out to validate the proposed method. In order to simplify the calculation, an equivalent model is carried out for experiment validation. Finally, in Section 5, the discussion and conclusion are summarized.

\section{Modal Extended Minimum Variance Unbiased Estimation}

2.1. System Model. The equation of motion of an $n$-degreesof-freedom building structure can be written as follows:

$$
\mathbf{M} \ddot{\mathbf{x}}(t)+\mathbf{C} \dot{\mathbf{x}}(t)+\mathbf{K} \mathbf{x}(t)=\mathbf{F}(t),
$$

where $\mathbf{M}, \mathbf{C}$, and $\mathbf{K}$ are the $n \times n$ structural mass, damping, and stiffness matrices, respectively; $\mathbf{F}(t)$ is the $n \times 1$ wind load vector; $\ddot{\mathbf{x}}(t), \dot{\mathbf{x}}(t)$, and $\mathbf{x}(t)$ are the $n \times 1$ wind-induced acceleration, velocity, and displacement vector, respectively.

Based on modal coordinate transformation theory [25], the structural displacement vector can be obtained as follows:

$$
\mathbf{x}(t)=\Phi \mathbf{Y}(t)
$$

where $\Phi$ is the $n \times n$ mass normalized modal shape matrix and $\mathbf{Y}(t)$ is the $n \times 1$ modal displacement vector. By premultiplying $\Phi^{T}$ and using equation (2), equation (1) can be written as follows:

$$
\mathbf{M}_{n} \ddot{\mathbf{Y}}_{n}(t)+\mathbf{C}_{n} \dot{\mathbf{Y}}_{n}(t)+\mathbf{K}_{n} \mathbf{Y}_{n}(t)=\mathbf{d}_{n}(t),
$$

where $\mathbf{M}_{n}=\Phi^{T} \mathbf{M} \Phi=\mathbf{I}$ is the modal mass matrix, $\mathbf{C}_{n}=\Phi^{T} \mathbf{C} \Phi=\Gamma_{n}$ is the modal damping matrix, $\mathbf{K}_{n}=\Phi^{T} \mathbf{K} \Phi=\Lambda_{n}$ is the modal stiffness matrix, and $\mathbf{d}_{n}(t)=$ $\Phi^{T} \mathbf{F}(t)$ is the modal wind load vector.

For proportionally damped system, the following can be obtained:

$$
\begin{aligned}
& \Gamma_{n}=\operatorname{diag}\left(2 \xi_{1} \omega_{1}, \ldots, 2 \xi_{i} \omega_{i}, \ldots, 2 \xi_{n} \omega_{n}\right), \\
& \Lambda_{n}=\operatorname{diag}\left(\omega_{1}^{2}, \ldots, \omega_{i}^{2}, \ldots, \omega_{n}^{2}\right),
\end{aligned}
$$

where $\omega_{i}$ is the $i$-th undamping natural frequency and $\xi_{i}$ is the $i$-th modal damping ratio.

Equation (3) can be rewritten as follows:

$$
\ddot{\mathbf{Y}}_{n}(t)+\Gamma_{n} \dot{\mathbf{Y}}_{n}(t)+\Lambda_{n} \mathbf{Y}_{n}(t)=\mathbf{d}_{n}(t)
$$

In general, due to the limitation of the number and location of the sensors, a reduced order representation of equation (6) is given:

$$
\ddot{\mathbf{Y}}_{m}(t)+\Gamma_{m} \dot{\mathbf{Y}}_{m}(t)+\Lambda_{m} \mathbf{Y}_{m}(t)=\mathbf{d}_{m}(t),
$$

where $\ddot{\mathbf{Y}}_{m}(t), \dot{\mathbf{Y}}_{m}(t)$, and $\mathbf{Y}_{m}(t)$ are the first $m$ order modal acceleration, modal velocity, and modal displacement vector, respectively. $\Gamma_{m}=\operatorname{diag}\left(2 \xi_{1} \omega_{1}, \ldots, 2 \xi_{i} \omega_{i}, \ldots, 2 \xi_{m} \omega_{m}\right)$ and $\Lambda_{m}=\operatorname{diag}\left(\omega_{1}^{2}, \ldots, \omega_{i}^{2}, \ldots, \omega_{m}^{2}\right)$.

The augmented state vector consists of the modal displacement, modal velocity, and the unknown structural parameters:

$$
\mathbf{Z}(t)=\left[\begin{array}{lll}
\mathbf{Y}_{m}^{T}(t) & \dot{\mathbf{Y}}_{m}^{T}(t) & \boldsymbol{\theta}_{p}^{T}
\end{array}\right]^{T},
$$

where $\boldsymbol{\theta}_{p}=\left[k_{1}, k_{2}, \ldots, k_{n}, \alpha, \beta\right]^{T}$ denotes the $p \times 1$ unknown structural parameters vector. $k_{i}$ is the $i$-th structural stiffness coefficient. $\alpha$ and $\beta$ are Rayleigh damping coefficients. Assuming that the unknown structural parameters are time invariant, the first-order differential equation of equation (8) can be obtained as follows: 


$$
\begin{aligned}
\dot{\mathbf{Z}}(t) & =\left[\begin{array}{c}
\dot{\mathbf{Y}}_{m}(t) \\
\ddot{\mathbf{Y}}_{m}(t) \\
0
\end{array}\right]=\left[\begin{array}{c}
\dot{\mathbf{Y}}_{m}(t) \\
\mathbf{d}_{m}(t)-\Gamma_{m} \dot{\mathbf{Y}}_{m}(t)-\Lambda_{m} \mathbf{Y}_{m}(t) \\
0
\end{array}\right] \\
& =g\left(\mathbf{Z}(t), \mathbf{d}_{m}(t)\right),
\end{aligned}
$$

where $g\left(\mathbf{Z}(t), \mathbf{d}_{m}(t)\right)$ is a nonlinear function consisting of the state vector, modal wind load vector, and time $t$.

Denote that $t_{k}=k \times \Delta t$ with $\Delta t$ as the sampling interval and define $\widehat{\mathbf{Z}}_{k \mid k}$ and $\widehat{\mathbf{d}}_{k}$ as the estimated values of $\mathbf{Z}_{k}$ and $\mathbf{d}_{k}$ at time $t_{k}$, respectively. Considering the process noise, the linearized expression of equation (9) can be expressed as follows:

$$
\begin{aligned}
g\left(\mathbf{Z}_{k}, \mathbf{d}_{k}\right)= & g\left(\widehat{\mathbf{Z}}_{k \mid k}, \widehat{\mathbf{d}}_{k}, k \Delta t\right)+\mathbf{G}_{k \mid k}^{\mathbf{Z}}\left(\mathbf{Z}_{k}-\widehat{\mathbf{Z}}_{k \mid k}\right) \\
& +\mathbf{G}_{k \mid k}^{d}\left(\mathbf{d}_{k}-\widehat{\mathbf{d}}_{k}\right)+\mathbf{w}_{k},
\end{aligned}
$$

where $\mathbf{w}_{k}$ is the process noise vector with a zero mean and covariance matrix $\mathbf{Q}_{k}=E\left[\mathbf{w}_{k} \mathbf{w}_{k}^{T}\right]$.

Furthermore, the following is obtained [26]:

$$
\begin{aligned}
& \mathbf{G}_{k \mid k}^{\mathbf{d}}=\left.\frac{\partial g\left(\mathbf{Z}_{k}, \mathbf{d}_{k}\right)}{\partial \mathbf{d}_{k}}\right|_{\mathbf{Z}_{k}=\widehat{\mathbf{Z}}_{k \mid k}, \mathbf{d}_{k}=\widehat{\mathbf{d}}_{k}}=\left[\begin{array}{l}
0 \\
\mathbf{I} \\
0
\end{array}\right], \\
& \mathbf{G}_{k \mid k}^{\mathbf{Z}}=\left.\frac{\partial g\left(\mathbf{Z}_{k}, \mathbf{d}_{k}\right)}{\partial \mathbf{Z}_{k}}\right|_{\mathbf{Z}_{k}=\widehat{\mathbf{Z}}_{k \mid k}, \mathbf{d}_{k}=\widehat{\mathbf{d}}_{k}}
\end{aligned}
$$

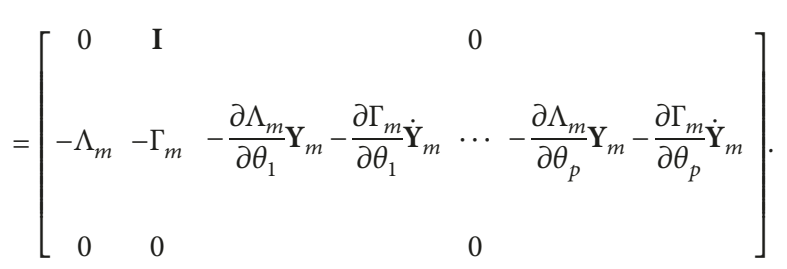

By substituting $\dot{\mathbf{Z}}_{k}=g\left(\mathbf{Z}_{k}, \mathbf{d}_{k}\right)=\left(\mathbf{Z}_{k+1}-\mathbf{Z}_{k}\right) /(\Delta t)$ into the left side of equation (9), the state space equation can be obtained:

$$
\begin{aligned}
\mathbf{Z}_{k+1}= & \mathbf{Z}_{k}+\Delta t\left[g\left(\widehat{\mathbf{Z}}_{k \mid k}, \widehat{\mathbf{d}}_{k}\right)+\mathbf{G}_{k \mid k}^{Z}\left(\mathbf{Z}_{k}-\widehat{\mathbf{Z}}_{k \mid k}\right)+\mathbf{G}_{k \mid k}^{d}\left(\mathbf{d}_{k}-\widehat{\mathbf{d}}_{k}\right)\right] \\
& +\Delta t \cdot \mathbf{w}_{k} .
\end{aligned}
$$

Only the partial wind-induced displacement and acceleration responses are measured. The measurement vector is expressed as follows:

$$
\mathbf{y}=\left[\begin{array}{c}
\mathbf{x}_{d} \\
\ddot{\mathbf{x}}_{a}
\end{array}\right],
$$

where $\mathbf{x}_{d}$ denotes $d \times 1$ wind-induced displacement responses and $\ddot{\mathbf{x}}_{a}$ denotes $a \times 1$ wind-induced acceleration responses.

Using modal coordinate transformation theory, the measurement equation at the $k$-th time step can be expressed as follows:

$$
\begin{aligned}
\mathbf{y}_{k} & =\left[\begin{array}{c}
\Delta \mathbf{x}_{d} \\
\ddot{\mathbf{x}}_{a}
\end{array}\right] \approx\left[\begin{array}{c}
D_{d} \Phi_{n \times m} \mathbf{Y}_{m} \\
D_{a} \Phi_{n \times m} \ddot{\mathbf{Y}}_{m}
\end{array}\right] \\
& =\left[\begin{array}{c}
D_{d} \Phi_{n \times m} \mathbf{Y}_{m} \\
D_{a} \Phi_{n \times m}\left(\mathbf{d}_{m}-\Gamma_{m} \dot{\mathbf{Y}}_{m}-\Lambda_{m} \mathbf{Y}_{m}\right)
\end{array}\right]=h\left(\mathbf{Z}_{k}\right)+\mathbf{H}_{k}^{\mathbf{d}} \mathbf{d}_{k},
\end{aligned}
$$

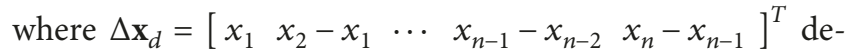
notes the interstory displacements, $D_{d}$ is the $d \times n$ mapping matrix associated with the DOFs of the measured displacement, and $D_{a}$ is the $a \times n$ mapping matrix associated with the DOFs of the measured acceleration.

Furthermore, the following is obtained:

$$
\begin{aligned}
h\left(\mathbf{Z}_{k}\right) & =\left[\begin{array}{c}
D_{d} \Phi_{n \times m} \mathbf{Y}_{m} \\
-D_{a} \Phi_{n \times m}\left(\Gamma_{m} \dot{\mathbf{Y}}_{m}+\Lambda_{m} \mathbf{Y}_{m}\right)
\end{array}\right], \\
\mathbf{H}_{k}^{\mathbf{d}} & =\left[\begin{array}{c}
0 \\
D_{a} \Phi_{n \times m} \mathbf{d}_{m}
\end{array}\right] .
\end{aligned}
$$

Considering the measurement noise, the linearized measurement equation can be expressed as follows:

$$
\mathbf{y}_{k}=h\left(\widehat{\mathbf{Z}}_{k \mid k-1}\right)+\mathbf{H}_{k}^{\mathbf{Z}}\left(\mathbf{Z}_{k}-\widehat{\mathbf{Z}}_{k \mid k-1}\right)+\mathbf{H}_{k} \mathbf{d}_{k}+\mathbf{v}_{k} \text {, }
$$

where $\mathbf{v}_{k}$ is the measurement noise vector at the $k$-th time step with zero mean and covariance $\mathbf{R}_{k}=E\left[\mathbf{v}_{k} \mathbf{v}_{k}^{T}\right]$.

Furthermore, the following is obtained:

$$
\begin{aligned}
& \mathbf{H}_{k}=\left[\begin{array}{c}
0 \\
D_{a} \Phi_{n \times m}
\end{array}\right],
\end{aligned}
$$

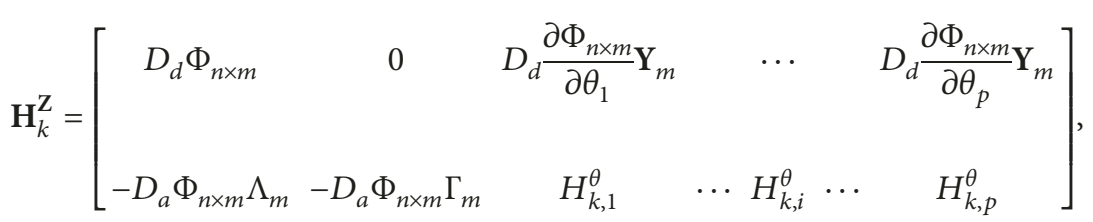


where

$$
\begin{aligned}
H_{k, i}^{\theta}= & -D_{a} \frac{\partial \Phi_{n \times m}}{\partial \theta_{i}}\left(\Gamma_{m} \dot{\mathbf{Y}}_{m}+\Lambda_{m} \mathbf{Y}_{m}\right) \\
& -D_{a} \Phi_{n \times m}\left(\frac{\partial \Gamma_{m}}{\partial \theta_{i}} \dot{\mathbf{Y}}_{m}+\frac{\partial \Lambda_{m}}{\partial \theta_{i}} \dot{\mathbf{Y}}_{m}\right)
\end{aligned}
$$

2.2. Eigenvalue and Eigenvector Sensitivity. The changes in the eigenvalues and eigenvectors of the system due to changes in system parameters are used to calculate matrix $\mathbf{G}_{k \mid k}^{\mathbf{Z}}$ and $\mathbf{H}_{k}^{\mathbf{Z}}$. For the case $\boldsymbol{\theta}=\left[k_{1}, k_{2}, \ldots, k_{n}, \alpha, \beta\right]^{T}$, the structural stiffness coefficient and damping coefficient are chosen as the unknown parameters. The eigenvalue problem of proportionally damped systems can be solved according to [27] as follows:

$$
\frac{\partial \lambda_{l}}{\partial \theta_{j}}=\frac{\varphi_{l}^{T}\left(\left(\partial \mathbf{K} / \partial \theta_{j}\right)-\lambda_{l}\left(\partial \mathbf{M} / \partial \theta_{j}\right)\right)}{\varphi_{l}^{T} \mathbf{M} \varphi_{l}},
$$

where $\lambda_{l}=\omega_{l}^{2}$ is the $l$-th eigenvalue, $\varphi_{l}$ is the $l$-th eigenvector, and $\theta_{j}$ is the $j$-th unknown parameter. Assuming that $m$ modes are used for joint state-parameter-input estimation for an $n$-degrees-of-freedom, the eigenvector derivative can be calculated based on Wang's method [28], as shown in the following equation:

$$
\frac{\partial \varphi_{l}}{\partial \theta_{j}}=\sum_{i=1}^{m} \bar{c}_{i} \varphi_{i}+d_{l} \oplus_{l},
$$

where

$$
\begin{aligned}
\bar{c}_{i} & =-\frac{\varphi_{i}^{T}\left(\left(\partial \mathbf{K} / \partial \theta_{j}\right)-\left(\partial \lambda_{l} / \partial \theta_{j}\right) \mathbf{M}-\lambda_{l}\left(\partial \mathbf{M} / \partial \theta_{j}\right)\right) \varphi_{l}}{\lambda_{i}-\lambda_{l}}, \\
\omega_{l} & =\mathbf{K}^{-1} \eta_{l}-\sum_{i=1}^{m} \frac{\varphi_{i}^{T} \eta_{l} \varphi_{i}}{\lambda_{i}}, \\
d_{l} & =\frac{\omega_{l}^{T} \eta_{l}}{\Theta_{l}^{T}\left(\mathbf{K}-\lambda_{l} \mathbf{M}\right) \omega_{l}}, \\
\eta_{l} & =-\left(\frac{\partial \mathbf{K}}{\partial \theta_{j}}-\frac{\partial \lambda_{l}}{\partial \theta_{j}} \mathbf{M}-\lambda_{l} \frac{\partial \mathbf{M}}{\partial \theta_{j}}\right) \varphi_{l} .
\end{aligned}
$$

Thus, the derivative of eigenvalue matrix $\Lambda$ subject to structural parameter $\theta_{j}$ can then be obtained based on equation (19):

$$
\frac{\partial \boldsymbol{\Lambda}}{\partial \theta_{j}}= \begin{cases}\operatorname{diag}\left(\frac{\partial \lambda_{1}}{\partial \theta_{j}} \frac{\partial \lambda_{2}}{\partial \theta_{j}} \cdots \frac{\partial \lambda_{m}}{\partial \theta_{j}}\right), & j=1,2, \ldots, n, \\ 0, & j=n+1, n+2 .\end{cases}
$$

The sensitively of eigenvector matrix $\Phi$ to the parameter $\theta_{j}$ can be given according to equation (20):

$$
\frac{\partial \Phi}{\partial \theta_{j}}= \begin{cases}\operatorname{diag}\left(\frac{\partial \varphi_{1}}{\partial \theta_{j}} \frac{\partial \varphi_{2}}{\partial \theta_{j}} \cdots \frac{\partial \varphi_{m}}{\partial \theta_{j}}\right), & j=1,2, \ldots, n \\ 0, & j=n+1, n+2 .\end{cases}
$$

The derivative of damping matrix $\Gamma$ subject to structural parameter $\theta_{j}$ can then be calculated as follows:

$$
\frac{\partial \Gamma}{\partial \theta_{j}}= \begin{cases}\operatorname{diag}\left(\beta \frac{\partial \lambda_{1}}{\partial \theta_{j}} \beta \frac{\partial \lambda_{2}}{\partial \theta_{j}} \cdots \beta \frac{\partial \lambda_{m}}{\partial \theta_{j}}\right), & j=1,2, \ldots, n, \\ \operatorname{diag}(11 \cdots 1), & j=n+1, \\ \operatorname{diag}\left(\lambda_{1} \lambda_{2} \cdots \lambda_{m}\right), & j=n+2 .\end{cases}
$$

For the case $\boldsymbol{\theta}=\left[\omega_{1}, \omega_{2}, \ldots, \omega_{m}, \xi_{1}, \xi_{2}, \ldots, \xi_{m}\right]^{T}$, the natural frequency $\omega$ and damping ratio $\xi$ are chosen as unknown parameters. The eigenvalue and eigenvector sensitivity can be calculated based on [29] as follows:

$$
\begin{aligned}
& \frac{\partial \lambda_{l}}{\partial \theta_{j}}= \begin{cases}2 \omega_{l}, & j=l, \\
0, & j \neq l,\end{cases} \\
& \frac{\partial \varphi_{l}}{\partial \theta_{j}}=0 .
\end{aligned}
$$

According to equation (4), the following equation can be obtained:

$$
\frac{\partial \gamma_{l}}{\partial \theta_{j}}= \begin{cases}2 \xi_{l}, & j=l, \\ 2 \omega_{l}, & j=l+m, \\ 0, & \text { else, }\end{cases}
$$

in which $\gamma_{l}=2 \omega_{l} \xi_{l}$ is the $l$-th diagonal element in the $\Gamma$ matrix.

Then, the derivative of the damping matrix subject to modal parameter $\theta_{j}$ can then be calculated as follows:

$$
\frac{\partial \Gamma}{\partial \theta_{j}}=\operatorname{diag}\left(\frac{\partial \gamma_{1}}{\partial \theta_{j}} \frac{\partial \gamma_{2}}{\partial \theta_{j}} \cdots \frac{\partial \gamma_{m}}{\partial \theta_{j}}\right) .
$$

The derivative of eigenvalue matrix $\boldsymbol{\Lambda}$ subject to modal parameter $\theta_{j}$ can then be obtained based on equation (25):

$$
\frac{\partial \boldsymbol{\Lambda}}{\partial \theta_{j}}=\operatorname{diag}\left(\frac{\partial \omega_{1}^{2}}{\partial \theta_{j}} \frac{\partial \omega_{2}^{2}}{\partial \theta_{j}} \cdots \frac{\partial \omega_{m}^{2}}{\partial \theta_{j}}\right) .
$$

The sensitively of eigenvector matrix $\Phi$ to the modal parameter $\theta_{j}$ can be given:

$$
\frac{\partial \Phi}{\partial \theta_{j}}=0
$$




\subsection{Modal Extended Minimum Variance Unbiased Estimation}

2.3.1. Time Update. The time update for the predicted state estimate $\widehat{\mathbf{Z}}_{k+1 \mid k}$ at time $t=(k+1) \times \Delta t$ can be calculated according to equation (12) as follows:

$$
\widehat{\mathbf{Z}}_{k+1 \mid k}=\widehat{\mathbf{Z}}_{k \mid k}+\Delta t \cdot g\left(\widehat{\mathbf{Z}}_{k \mid k}, \widehat{\mathbf{d}}_{k}, k \Delta t\right) \text {. }
$$

According to equations (10) and (31), the error of the predicted state estimate $\widehat{\mathbf{Z}}_{k+1 \mid k}$ can be calculated as follows:

$$
\boldsymbol{\varepsilon}_{k+1 \mid k}^{\mathbf{Z}}=\mathbf{Z}_{k+1}-\widehat{\mathbf{Z}}_{k+1 \mid k}=\mathbf{A}_{k} \boldsymbol{\varepsilon}_{k \mid k}^{\mathbf{Z}}+\mathbf{B}_{k} \boldsymbol{\varepsilon}_{k}^{\mathbf{d}}+\Delta t \cdot \mathbf{w}_{k},
$$

where the coefficient matrices $\mathbf{A}_{k}=\left(\mathbf{I}+\Delta t \cdot \mathbf{G}_{k \mid k}^{\mathbf{Z}}\right)$ and $\mathbf{B}_{k}=\Delta t \cdot \mathbf{G}_{k \mid k}^{\mathbf{d}} \cdot \boldsymbol{\varepsilon}_{k \mid k}^{\mathbf{Z}}=\mathbf{Z}_{k}-\widehat{\mathbf{Z}}_{k \mid k}$ and $\boldsymbol{\varepsilon}_{k}^{\mathbf{d}}=\mathbf{d}_{k}-\widehat{\mathbf{d}}_{k}$ are the estimation errors of state and modal wind load at time $t=k \times \Delta t$, respectively.

The covariance matrix $\mathbf{P}_{k+1 \mid k}^{Z}$ related to the predicted state estimate $\widehat{\mathbf{Z}}_{k+1 \mid k}$ can then be expressed as follows:

$$
\mathbf{P}_{k+1 \mid k}^{\mathbf{Z}}=\left[\begin{array}{ll}
\mathbf{A}_{k} & \mathbf{B}_{k}
\end{array}\right]\left[\begin{array}{cc}
\mathbf{P}_{k \mid k}^{\mathbf{Z}} & \mathbf{P}_{k}^{Z d} \\
\mathbf{P}_{k}^{d \mathbf{Z}} & \mathbf{P}_{k}^{d}
\end{array}\right]\left[\begin{array}{c}
\mathbf{A}_{k}^{T} \\
\mathbf{B}_{k}^{T}
\end{array}\right]+\Delta t^{2} \cdot \mathbf{Q}_{k},
$$

where $\quad \mathbf{P}_{k \mid k}^{\mathbf{Z}}=E\left[\left(\boldsymbol{\varepsilon}_{k \mid k}^{\mathbf{Z}}\right)\left(\boldsymbol{\varepsilon}_{k \mid k}^{\mathbf{Z}}\right)^{T}\right], \quad \mathbf{P}_{k}^{\mathbf{d}}=E\left[\left(\boldsymbol{\varepsilon}_{k}^{\mathbf{d}}\right)\left(\boldsymbol{\varepsilon}_{k}^{\mathbf{d}}\right)^{T}\right], \quad$ and $\mathbf{P}_{k}^{\mathbf{Z d}}=\left(\mathbf{P}_{k}^{\mathrm{dZ}}\right)^{T}=E\left[\left(\boldsymbol{\varepsilon}_{k \mid k}^{\mathbf{Z}}\right)\left(\boldsymbol{\varepsilon}_{k}^{\mathbf{d}}\right)^{T}\right]$.

2.3.2. Modal Wind Load Estimation. Defining the innovation $\widehat{\mathbf{y}}_{k+1}=\mathbf{y}_{k+1}-h\left(\widehat{\mathbf{Z}}_{k+1 \mid k}\right)$, according to equation (16), the following equation can be obtained:

$$
\widehat{\mathbf{y}}_{k+1}=\mathbf{H}_{k+1} \mathbf{d}_{k+1}+\mathbf{e}_{k+1} \text {, }
$$

where the error $\mathbf{e}_{k+1}$ is given by the following equation:

$$
\mathbf{e}_{k+1}=\mathbf{H}_{k+1}^{\mathrm{Z}} \boldsymbol{\varepsilon}_{k+1 \mid k}^{\mathbf{Z}}+\mathbf{v}_{k+1} .
$$

As $\widehat{\mathbf{Z}}_{k+1 \mid k}$ is unbiased, it follows from equation (35) that $E\left[\mathbf{e}_{k+1}\right]=0$, and consequently according to equation (34), $E\left[\widehat{\mathbf{y}}_{k+1}\right]=\mathbf{H}_{k+1} E\left[\mathbf{d}_{k+1}\right]$ can be obtained. Assume that the form of the estimated modal wind load $\widehat{\mathbf{d}}_{k+1}$ is as follows:

$$
\widehat{\mathbf{d}}_{k+1}=\mathbf{S}_{k+1} \widehat{\mathbf{y}}_{k+1}=\mathbf{S}_{k+1}\left(\mathbf{H}_{k+1} \mathbf{d}_{k+1}+\mathbf{e}_{k+1}\right) \text {. }
$$

Therefore, $E\left(\widehat{\mathbf{d}}_{k+1}\right)=\mathbf{S}_{k+1} \mathbf{H}_{k+1} E\left(\mathbf{d}_{k+1}\right)$ can be obtained. This indicates that the estimated modal wind load $\widehat{\mathbf{d}}_{k+1}$ is unbiased if and only if $\mathbf{S}_{k+1}$ satisfies $\mathbf{S}_{k+1} \mathbf{H}_{k+1}=\mathbf{I}$.

According to equation (35), the covariance of the error $\mathbf{e}_{k+1}$ can be obtained as follows:

$$
\mathbf{P}_{k+1}^{\mathbf{e}}=E\left[\mathbf{e}_{k+1} \mathbf{e}_{k+1}^{T}\right]=\mathbf{H}_{k+1}^{\mathbf{Z}} \mathbf{P}_{k+1 \mid k}^{\mathbf{Z}}\left(\mathbf{H}_{k+1}^{\mathrm{Z}}\right)^{T}+\mathbf{R}_{k} .
$$

Generally, $\mathbf{P}_{k+1}^{\mathrm{e}} \neq c \mathbf{I}$, where $c$ is a positive real number. This indicates that equation (34) does not satisfy homoscedasticity. Therefore, the estimator given in equation (36) is not the minimum variance estimation of modal wind load according to the Gauss-Markov theorem [30].

To obtain the unbiased minimum variance estimation of modal wind load $\mathbf{d}_{k+1}$, the optimal value of matrix $\mathbf{S}_{k+1}$ in equation (36) should be determined. Assume that the covariance matrix $\mathbf{P}_{k+1}^{\mathbf{e}}$ in equation (37) is positive definite (i.e., $\mathbf{P}_{k+1}^{\mathbf{e}}>0$ ), an invertible matrix $\Psi_{k+1}$ satisfying $\Psi_{k+1} \Psi_{k+1}^{T}=$
$\mathbf{P}_{k+1}^{\mathbf{e}}$ can be found. By premultiplying $\Psi_{k+1}^{-1}$ to equation (34), one can obtain the following equation:

$$
\Psi_{k+1}^{-1} \widehat{\mathbf{y}}_{k+1}=\Psi_{k+1}^{-1} \mathbf{H}_{k+1} \mathbf{d}_{k+1}+\Psi_{k+1}^{-1} \mathbf{e}_{k+1} .
$$

Now the covariance $E\left[\left(\Psi_{k+1}^{-1} \mathbf{e}_{k+1}\right)\left(\Psi_{k+1}^{-1} \mathbf{e}_{k+1}\right)^{T}\right]=\mathbf{I}$, which satisfies homoscedasticity. Under the assumption that $\Psi_{k+1}^{-1} \mathbf{H}_{k+1}$ has full column rank, the unbiased minimum variance estimation of $\mathbf{d}_{k+1}$ can then be obtained based on the Gauss-Markov theorem [30] as follows:

$$
\widehat{\mathbf{d}}_{k+1}=\left[\mathbf{H}_{k+1}^{T}\left(\mathbf{P}_{k+1}^{\mathbf{e}}\right)^{-1} \mathbf{H}_{k+1}\right]^{-1} \mathbf{H}_{k+1}^{T}\left(\mathbf{P}_{k+1}^{\mathbf{e}}\right)^{-1}\left[\mathbf{y}_{k+1}-h\left(\widehat{\mathbf{Z}}_{k+1 \mid k}\right)\right] \text {. }
$$

Therefore, the optimal $\mathbf{S}_{k+1}$ is obtained:

$$
\mathbf{S}_{k+1}=\left[\mathbf{H}_{k+1}^{T}\left(\mathbf{P}_{k+1}^{\mathbf{e}}\right)^{-1} \mathbf{H}_{k+1}\right]^{-1} \mathbf{H}_{k+1}^{T}\left(\mathbf{P}_{k+1}^{\mathbf{e}}\right)^{-1} .
$$

The error of the estimated modal wind load $\widehat{\mathbf{d}}_{k+1}$ can be given based on equations (36) and (39):

$$
\begin{aligned}
\boldsymbol{\varepsilon}_{k+1}^{\mathbf{d}} & =\mathbf{d}_{k+1}-\widehat{\mathbf{d}}_{k+1} \\
& =\left(\mathbf{I}-\mathbf{S}_{k+1} \mathbf{H}_{k+1}\right) \mathbf{d}_{k+1}-\mathbf{S}_{k+1} \mathbf{e}_{k+1} \\
& =-\mathbf{S}_{k+1} \mathbf{e}_{k+1} .
\end{aligned}
$$

According to equation (41), the covariance matrix $\mathbf{P}_{k+1}^{\mathbf{d}}$ related to the estimated modal wind load $\widehat{\mathbf{d}}_{k+1}$ is calculated as follows:

$$
\mathbf{P}_{k+1}^{\mathbf{d}}=\mathbf{S}_{k+1} \mathbf{P}_{k+1}^{\mathbf{e}} \mathbf{S}_{k+1}^{T}=\left[\mathbf{H}_{k+1}^{T}\left(\mathbf{P}_{k+1}^{\mathbf{e}}\right)^{-1} \mathbf{H}_{k+1}\right]^{-1} .
$$

2.3.3. Measurement Update. Define the final form of the updated state estimate $\widehat{\mathbf{Z}}_{k+1 \mid k+1}$, as follows:

$$
\widehat{\mathbf{Z}}_{k+1 \mid k+1}=\widehat{\mathbf{Z}}_{k+1 \mid k}+\mathbf{L}_{k+1}\left[\mathbf{y}_{k+1}-h\left(\mathbf{Z}_{k+1 \mid k}\right)\right] \text {, }
$$

where $\mathbf{L}_{k+1}$ is the gain matrix. The error $\boldsymbol{\varepsilon}_{k+1 \mid k+1}^{\mathbf{Z}}$ of the updated state estimate $\widehat{\mathbf{Z}}_{k+1 \mid k+1}$ can be calculated according to equations (12) and (43):

$$
\boldsymbol{\varepsilon}_{k+1 \mid k+1}^{\mathbf{Z}}=\left(\mathbf{I}-\mathbf{L}_{k+1} \mathbf{H}_{k+1}^{\mathbf{Z}}\right) \boldsymbol{\varepsilon}_{k+1 \mid k}^{\mathbf{Z}}-\mathbf{L}_{k+1} \mathbf{H}_{k+1} \mathbf{d}_{k+1}-\mathbf{L}_{k+1} \mathbf{v}_{k+1} .
$$

Therefore, $E\left(\boldsymbol{\varepsilon}_{k+1 \mid k+1}^{\mathbf{Z}}\right)=-\mathbf{L}_{k+1} \mathbf{H}_{k+1} E\left(\mathbf{d}_{k+1}\right)$, which indicates that $\widehat{\mathbf{Z}}_{k+1 \mid k+1}$ is unbiased for all possible $\mathbf{d}_{k+1}$ if and only if

$$
\mathbf{L}_{k+1} \mathbf{H}_{k+1}=0 \text {. }
$$

Based on Equations (44) and (45), the covariance matrix $\mathbf{P}_{k+1 \mid k+1}^{Z}$ related to the updated state estimate $\widehat{\mathbf{Z}}_{k+1 \mid k+1}$ can be obtained as follows:

$$
\begin{aligned}
\mathbf{P}_{k+1 \mid k+1}^{\mathbf{Z}} & =E\left[\left(\boldsymbol{\varepsilon}_{k+1 \mid k+1}^{\mathbf{Z}}\right)\left(\boldsymbol{\varepsilon}_{k+1 \mid k+1}^{\mathbf{Z}}\right)^{T}\right] \\
& =\left(\mathbf{I}-\mathbf{L}_{k+1} \mathbf{H}_{k+1}^{\mathbf{Z}}\right) \mathbf{P}_{k+1 \mid k}^{\mathbf{Z}}\left(\mathbf{I}-\mathbf{L}_{k+1} \mathbf{H}_{k+1}^{\mathbf{Z}}\right)^{T}+\mathbf{L}_{k+1} \mathbf{R}_{k+1} \mathbf{L}_{k+1}^{T} .
\end{aligned}
$$

To obtain the unbiased minimum variance estimation of state $\mathbf{Z}_{k+1}$, the optimal value of the gain matrix $\mathbf{L}_{k+1}$ should be determined. Based on the Lagrange multipliers method 
[31], the optimal gain matrix $\mathbf{L}_{k+1}$ can be calculated by minimizing the trace of $\mathbf{P}_{k+1 \mid k+1}^{Z}$ under the unbiased condition shown in equation (45):

$$
\mathbf{L}_{k+1}=\mathbf{N}_{k+1}\left(\mathbf{I}-\mathbf{H}_{k+1} \mathbf{S}_{k+1}\right) \text {, }
$$

where

$$
\mathbf{N}_{k+1}=\mathbf{P}_{k+1 \mid k}^{\mathbf{Z}}\left(\mathbf{H}_{k+1}^{\mathbf{Z}}\right)^{T}\left(\mathbf{P}_{k+1}^{\mathbf{e}}\right)^{-1}
$$

By substituting equation (47) into (43), the unbiased minimum variance estimation of state $\mathbf{Z}_{k+1}$ can be calculated as follows:

$$
\begin{aligned}
\widehat{\mathbf{Z}}_{k+1 \mid k+1} & =\widehat{\mathbf{Z}}_{k+1 \mid k}+\mathbf{N}_{k+1}\left(\mathbf{I}-\mathbf{H}_{k+1} \mathbf{S}_{k+1}\right)\left[\mathbf{y}_{k+1}-h\left(\mathbf{Z}_{k+1 \mid k}\right)\right] \\
& =\widehat{\mathbf{Z}}_{k+1 \mid k}+\mathbf{N}_{k+1}\left[\mathbf{y}_{k+1}-h\left(\mathbf{Z}_{k+1 \mid k}\right)-\mathbf{H}_{k+1} \widehat{\mathbf{d}}_{k+1}\right] .
\end{aligned}
$$

Similarly, substituting equation (47) into (46), the covariance matrix $\mathbf{P}_{k+1 \mid k+1}^{\mathbf{Z}}$ related to $\widehat{\mathbf{Z}}_{k+1 \mid k+1}$ can be expressed as follows:

$$
\mathbf{P}_{k+1 \mid k+1}^{\mathbf{Z}}=\mathbf{P}_{k+1 \mid k}^{\mathbf{Z}}-\mathbf{N}_{k+1}\left(\mathbf{P}_{k+1}^{\mathbf{e}}-\mathbf{H}_{k+1} \mathbf{P}_{k+1}^{\mathbf{d}} \mathbf{H}_{k+1}^{T}\right)\left(\mathbf{N}_{k+1}\right)^{T} .
$$

Based on equations (41) and (44), the covariance matrices $\mathbf{P}_{k+1}^{\mathbf{Z d}}$ and $\mathbf{P}_{k+1}^{\mathrm{dZ}}$ can be obtained as follows:

$$
\mathbf{P}_{k+1}^{\mathbf{Z d}}=\left(\mathbf{P}_{k+1}^{\mathrm{dZ}}\right)^{T}=-\mathbf{P}_{k+1 \mid k}^{\mathbf{Z}}\left(\mathbf{H}_{k+1}^{\mathbf{Z}}\right)^{T}\left(\mathbf{S}_{k+1}\right)^{T} .
$$

Now the estimated displacement response $\widehat{\mathbf{x}}_{k+1}$, velocity response $\widehat{\dot{\mathbf{x}}}_{k+1}$, structural parameters $\widehat{\theta}_{k+1}$, and wind load $\widehat{\mathbf{F}}_{k+1}$ at time $t=(k+1) \times \Delta t$ can be calculated as follows:

$$
\begin{aligned}
\widehat{\mathbf{x}}_{k+1} & =\Phi_{n \times m} \widehat{\mathbf{Y}}_{m, k+1}, \\
\widehat{\dot{\mathbf{x}}}_{k+1} & =\Phi_{n \times m} \hat{\mathbf{Y}}_{m, k+1}, \\
\widehat{\theta}_{k+1} & =\widehat{\theta}_{p, k+1}, \\
\widehat{\mathbf{F}}_{k+1} & =\Phi_{n \times m}\left(\Phi_{n \times m}^{T} \Phi_{n \times m}\right)^{-1} \widehat{\mathbf{d}}_{k+1},
\end{aligned}
$$

where $\widehat{\mathbf{Y}}_{m, k+1}, \hat{\mathbf{Y}}_{m, k+1}$, and $\hat{\theta}_{p, k+1}$ are the estimation of modal displacement response, modal velocity response, and structural parameters, respectively, which are obtained from the state estimate $\widehat{\mathbf{Z}}_{k+1 \mid k+1}$.

\section{Numerical Simulation}

To verify the feasibility and accuracy of the proposed method, a ten-story shear building structure under wind load is considered. The mass coefficient of each floor is $m=10^{5} \mathrm{~kg}$, and the stiffness coefficient of each floor is $k=$ $2.45 \times 10^{8} \mathrm{~N} / \mathrm{m}$ The damping is assumed to be Rayleigh damping which is calculated as $\mathbf{C}=\alpha \mathbf{M}+\beta \mathbf{K}$ with proportional coefficients of $\alpha=0.557$ and $\beta=0.0034$. The corresponding damping ratio for the first two modes of vibration is approximate $5 \%$.

The fluctuating wind speed is numerically simulated based on the autoregressive model method. The power spectral density is Davenport spectral. The vertical wind profile is taken as the power profile with an exponent of $a=0.22$ and a reference height of $z_{G}=10 \mathrm{~m}$ according to the Chinese National Load Code [32]. The mean wind speed at the reference height is $10 \mathrm{~m} / \mathrm{s}$. Figure 1 shows the simulated fluctuating wind speed on the fifth and tenth floors. Figure 2 shows the comparison of the power spectral density between the simulated fluctuating wind speed and the Davenport spectral on the fifth and tenth floors. Figure 2 shows that the simulated power spectral density matches very well with the Davenport spectral. The wind load acting on the building structure is calculated according to [22]. The air density is assumed to be $\rho=1.29 \mathrm{~kg} / \mathrm{m}^{3}$. The drag coefficient is set to 1.3 , and the orthogonal exposed wind area of each floor is set to $50 \mathrm{~m}^{2}$.

3.1. Joint State/Parameter/Wind Load Estimation Based on Incomplete Measurements. In this section, the interstory displacement and acceleration taken as the "measurements" are calculated based on the Newmark- $\beta$ method and superimposed with $2 \%$ root mean square (RMS) white noise. Only seven sets of measurements including seven accelerations and seven interstory displacements are used for the estimation. The locations of the measurements are listed in Table 1. The unknown structural parameters are structural stiffness coefficients on each floor and the two Rayleigh damping coefficients. The initial value of the augmented state vector is $\mathbf{Z}_{1 \mid 0}=\left[\begin{array}{lllll}0_{1 \times 20} & 1.3 k & 1.3 \alpha & 1.3 \beta\end{array}\right]$, where $k=\left[k_{1}, k_{2}, \ldots, k_{9}, k_{10}\right]$. The initial error covariance matrix of the augmented state vector is $\mathbf{P}_{1 \mid 0}^{\mathbf{Z}}=\operatorname{diag}([(1,1$, $\left.\left.\ldots, 1)_{1 \times 20}\left(10^{23}, 10^{23}, \ldots, 10^{23}\right)_{1 \times 10}, 10^{7}, 10^{2}\right]\right)$. The covariance matrix of process noise is $\mathbf{Q}=10^{-2}$, and the covariance matrix of measurement noise is $\mathbf{R}=10^{-1}$. Figure 3 shows the comparison of the estimated structural displacement responses with exact values on the fifth and tenth floors for time and frequency domains. Figure 4 shows the comparison of the estimated structural velocity responses with exact values on the fifth and tenth floors for time and frequency domains. The estimated curves coincide with the exact curves. This indicates that the proposed method is capable of identifying structural responses. Furthermore, two obvious peaks at $1.185 \mathrm{~Hz}$ and $3.527 \mathrm{~Hz}$ can be obtained in Figures 3 and 4 . The two peaks correspond to the first two translational natural frequency of the building.

Moreover, based on the proposed method, the unknown wind load is identified using incomplete measurements. The identified wind load and the relative errors between the identified wind load and the exact one in percentage on the fifth and tenth floors of the numerical model are plotted in Figure 5. Figure 5 shows that the iteration process cannot converge immediately, but after approximately $8 \mathrm{~s}$, the relative errors are well converged to less than $5 \%$. Table 2 shows the mean errors and the RMS errors between the identified wind loads and the exact ones on each floor. From Table 2, the maximum mean errors and RMS errors of the identified wind loads are $4.12 \%$ and $4.56 \%$, respectively. This means that the identified wind loads match the exact ones very well after iterative convergence.

Figure 6 shows the estimated results of the fifth and tenth structural stiffness coefficients. It indicates that the stiffness 


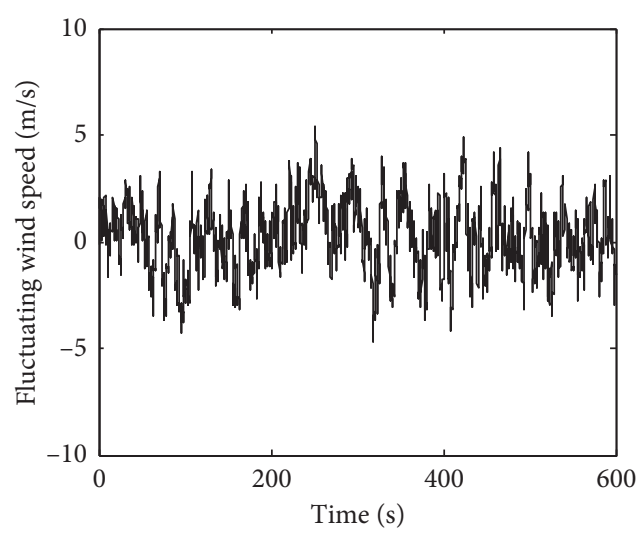

(a)

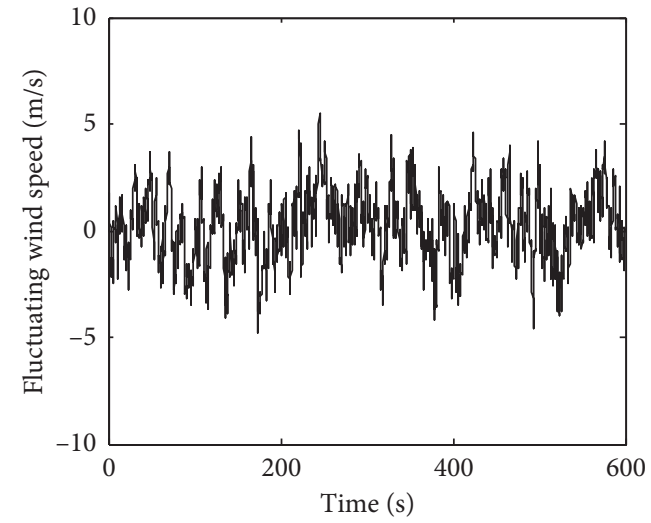

(b)

Figure 1: Simulated fluctuating wind speed on the (a) fifth floor and (b) tenth floor.

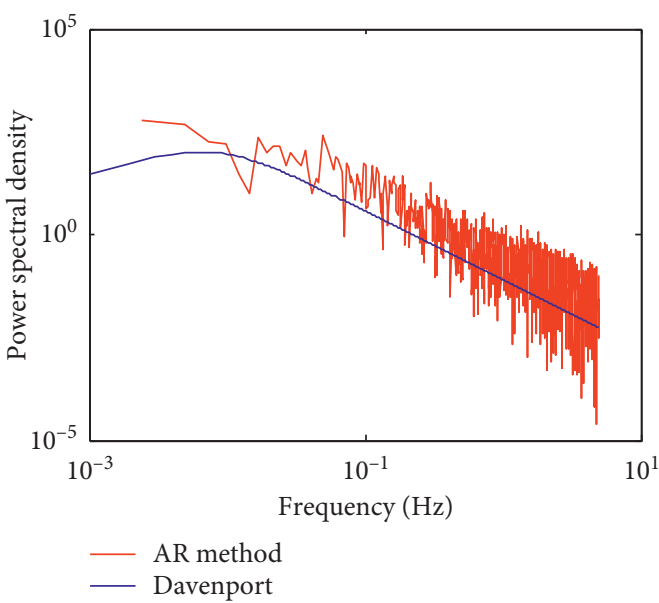

(a)

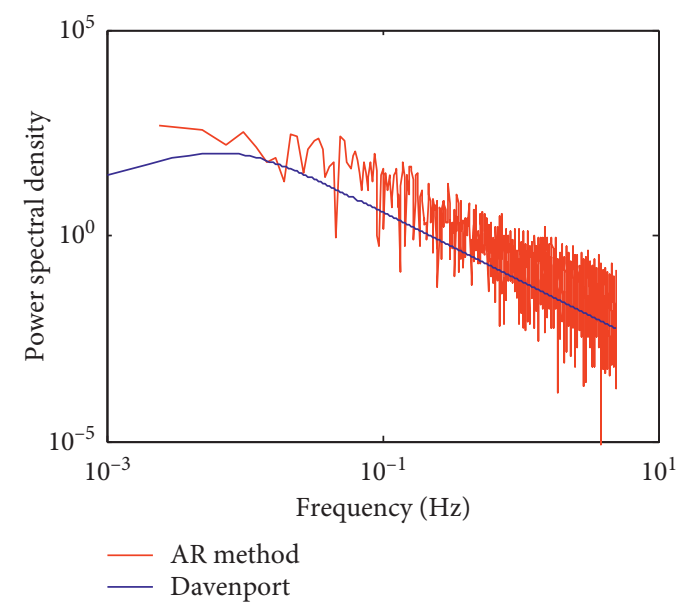

(b)

FIGURE 2: Comparison of the power spectral density between the simulated and Davenport spectral on the (a) fifth floor and (b) tenth floor.

TABLE 1: Number of measurements and corresponding locations.

\begin{tabular}{lc}
\hline Number of measurements & Location (floor) \\
\hline 7 & $2,3,4,5,7,9,10$ \\
\hline
\end{tabular}

coefficients can converge to the real value within $2 \mathrm{~s}$. The estimation results of Rayleigh damping coefficients $\alpha$ and $\beta$ are plotted in Figure 7. Compared to the stiffness coefficient, the damping coefficient converges slightly slower and can converge to a real value within approximately 5 s. Table 3 lists the estimated values and errors of the structural parameters. The maximum error for the stiffness coefficient is $4.30 \%$. The estimated errors for the damping coefficients $\alpha$ and $\beta$ are $4.25 \%$ and $4.24 \%$, respectively. This indicates that the proposed method is capable of identifying the structural parameters with incomplete measurements.

3.1.1. Effect of Sampling Duration. To investigate the stability of the proposed method, the effect of the sampling duration on wind load and structural parameter estimation is discussed. The number and location of measurements are the same as in Table 1 . The total duration of the measurements is set to $1 \mathrm{~s}, 10 \mathrm{~s}, 30 \mathrm{~s}$, and $60 \mathrm{~s}$. Table 4 shows the RMS errors of the estimated wind load on each floor under different sampling durations. The estimated results of the structural parameters are given in Table 5. From Table 4, the maximum RMS errors of wind load under $1 \mathrm{~s}, 10 \mathrm{~s}, 30 \mathrm{~s}$, and 60 s are $14.23 \%, 7.68 \%, 4.58 \%$, and $4.55 \%$, respectively. From Table 5, the maximum errors of the structural parameters under $1 \mathrm{~s}, 10 \mathrm{~s}, 30 \mathrm{~s}$, and $60 \mathrm{~s}$ are $32.78 \%, 6.99 \%$, $4.66 \%$, and $4.25 \%$, respectively. This indicates that the estimation errors decrease as the time duration increases. Table 5 shows that the estimation errors of the wind load and structural parameters are all less than 5\% when the sampling duration reaches $30 \mathrm{~s}$. Furthermore, comparing the estimated results between $30 \mathrm{~s}$ and $60 \mathrm{~s}$ shows that the estimation accuracy increases slightly. Therefore, considering the computational costs, the sampling duration of $30 \mathrm{~s}$ is adequate for this numerical simulation. 


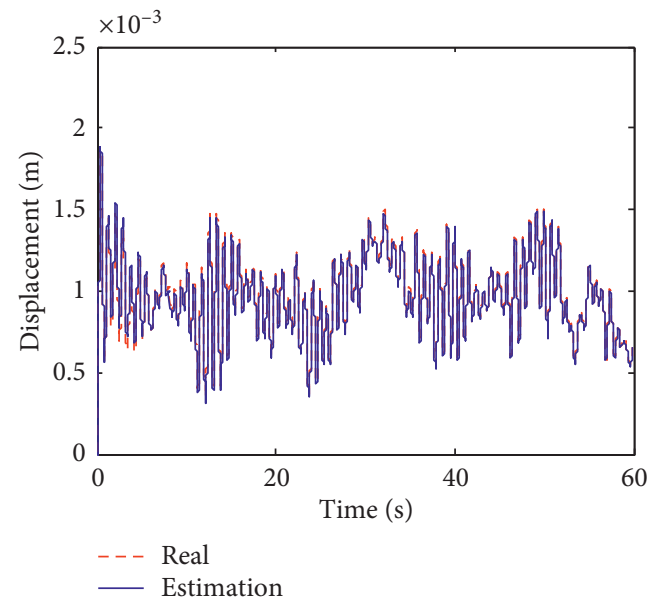

(a)

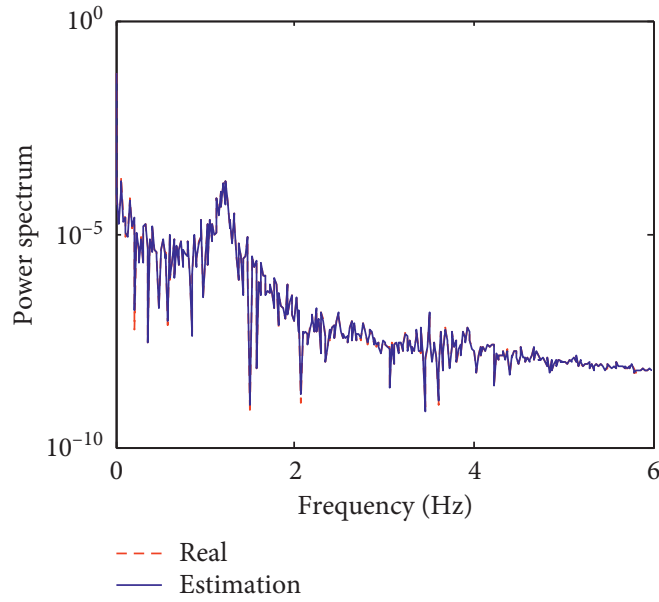

(c)

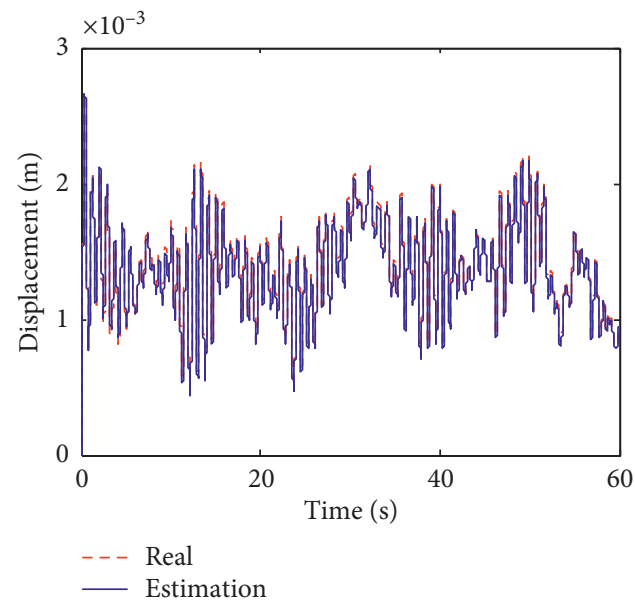

(b)

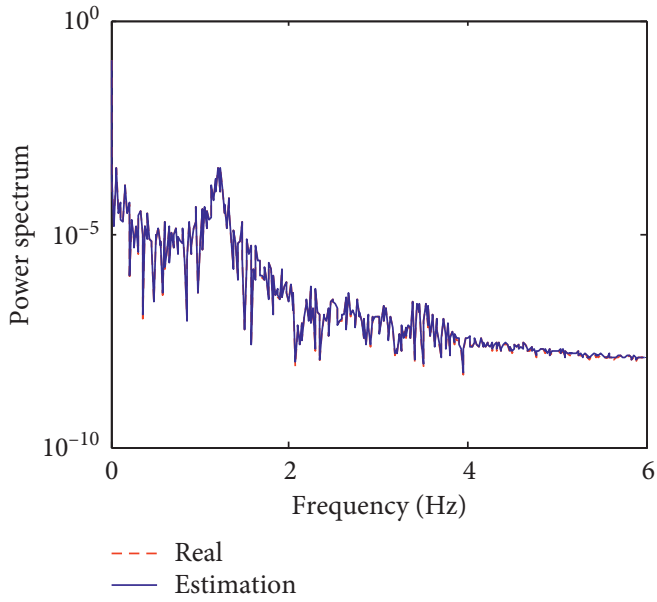

(d)

Figure 3: Comparison of the structural displacement responses for time and frequency domains. Displacement vs time on the (a) fifth floor and (b) tenth floor. Frequency vs power spectrum on the (c) fifth floor and (d) tenth floor.

3.1.2. Effect of the Number of Measurements. This section discusses the influence of the number of measurements for joint state/parameter/wind load estimation. The considered set of measurements is four to nine, and each set of measurements includes interstory displacement and acceleration responses. Table 6 shows the number of measurements and the corresponding locations.

The time histories of the estimated wind loads on the fifth and tenth floors under different numbers of measurements are plotted in Figure 8. Figure 8 shows that the variation trends of the identified wind loads are identical to the exact ones. However, there is an obvious error between the estimated value and the exact one when the number of measurements is less than six. The RMS errors of the identified wind load on each floor under different numbers of measurements are listed in Table 7 . Table 7 shows that as the number of measurements increases, the RMS error of the estimated wind load decreases. The maximum error under six, five, and four sets of measurements is $5.33 \%, 7.08 \%$, and $10.78 \%$, respectively. This indicates that the estimation error increases significantly when the number of measurements is less than six.

The time histories of the estimated errors of the fifth and tenth structural stiffness coefficients for different numbers of measurements are shown in Figure 9. Figure 9 shows that at the beginning of the iteration are some fluctuations. However, after approximately $2 \mathrm{~s}$, the iteration converges to the true value. Figure 10 plots the estimated errors of damping coefficients $\alpha$ and $\beta$. Figure 10 shows that both $\alpha$ and $\beta$ have a large fluctuation at the beginning of the iteration, and they converge to the true value after approximately $10 \mathrm{~s}$ under more than seven measurements. However, the estimation results fluctuate around the true value when the number of measurements is less than seven. This indicates that damping coefficients are sensitive to the number of measurements and fluctuate around the true value if the number of measurements is insufficient. Table 8 gives the estimation results of the structural parameters with the number of measurements (i.e., from 4 to 9 ). The maximum errors of the estimated parameters under four to nine 


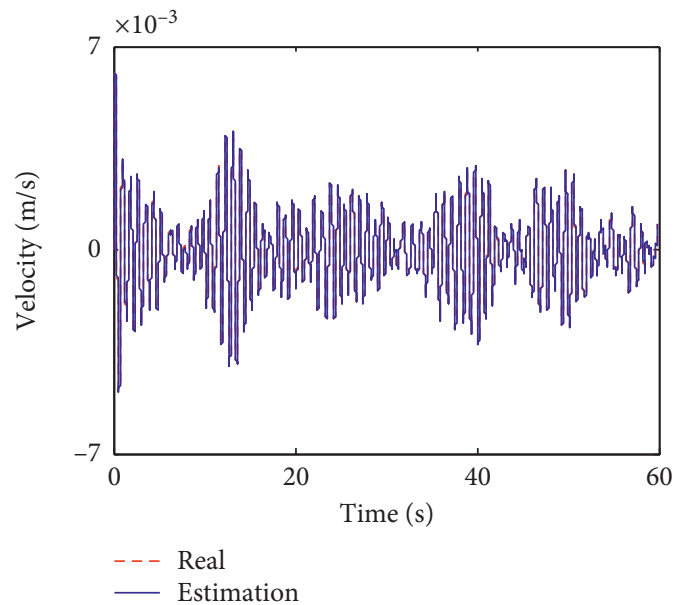

(a)

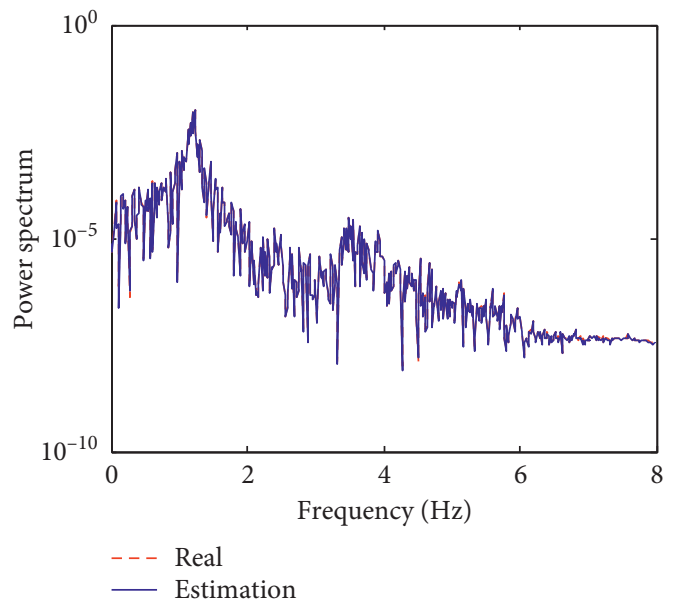

(c)

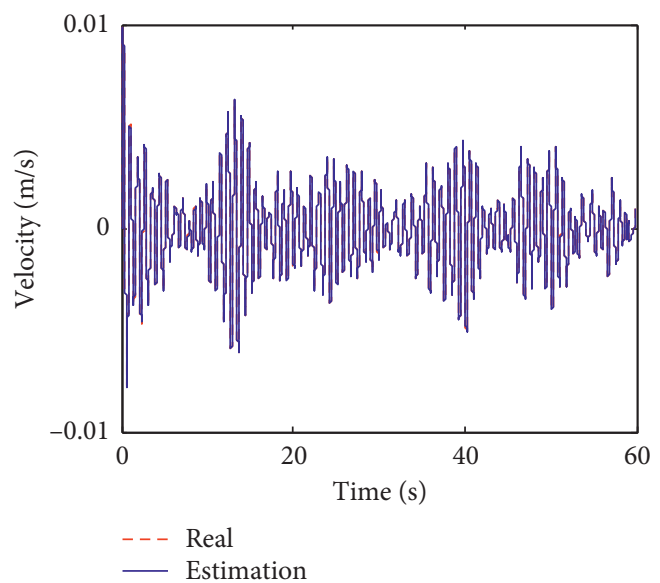

(b)

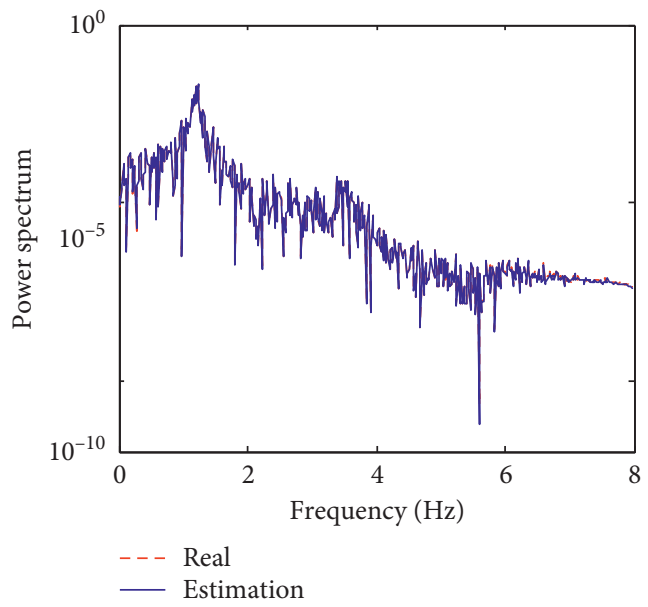

(d)

FIgURE 4: Comparison of the structural velocity responses for time and frequency domains. Time vs velocity on the (a) fifth floor and (b) tenth floor. Frequency vs power spectrum on the (c) fifth floor and (d) tenth floor.

measurements are $13.01 \%, 11.76 \%, 9.83 \%, 4.30 \%, 3.71 \%$, and $3.63 \%$, respectively. It indicates that as the number of measurements increases, the estimation accuracy of the structural parameters increases. The maximum errors of the structural stiffness coefficient and the damping coefficients $\alpha$ and $\beta$ under six sets of measurements are $5.98 \%$, $9.83 \%$, and $5.33 \%$, respectively. However, the estimation errors of each structural parameter are less than $5 \%$ under seven sets of measurements. The results indicate that, for this particular example, at least seven sets of measurements should be used.

\section{Validation with Wind Tunnel Tests}

In order to verify the effectiveness of the proposed method in practical engineering application, a tall building with 58 floors is considered as an example in this study. The size of the building is $234 \mathrm{~m}$ (height) $\times 39 \mathrm{~m}$ (width) $\times 39 \mathrm{~m}$ (length). The synchronous multipressure scanning system wind tunnel test for simultaneous estimation of state, unknown structural parameters, and wind load was conducted in wind environment wind tunnel laboratory at Harbin Institute of Technology (Shenzhen), China. According to Chinese National Load Code (GB 50009-2012) [32], the site around the test building is taken as terrain $\mathrm{C}$. The wind profile is regarded as power law with an exponent of 0.22 . The length scale of this wind tunnel test is $1: 300$. Figure 11 shows the simulated profiles of mean wind speed and turbulence intensity.

The model has the same length scale with that of wind field simulation, i.e., $1: 300$. The size of the model is $780 \mathrm{~mm}$ (height) $\times 130 \mathrm{~mm}$ (width) $\times 130 \mathrm{~mm}$ (length), as shown in Figure 12. In this wind tunnel test, wind direction was defined as an angle $\theta_{\mathrm{d}}$ from $0^{\circ}$ to $360^{\circ}$ with increments of $15^{\circ}$, as shown in Figure 13. The total number of the pressure taps installed on the building was 441 with 98 on each side surface and 49 on top surface. The pressure data were collected using an microelectronic pressure scanner system made by PSI. The data sampling frequency was $330 \mathrm{~Hz}$, and the sampling length was $120 \mathrm{~s}$. The wind speed at the top of the model with a 10-year return period is $39.6 \mathrm{~m} / \mathrm{s}$ based on Chinese $\mathrm{Na}$ tional Load Code [32]. 


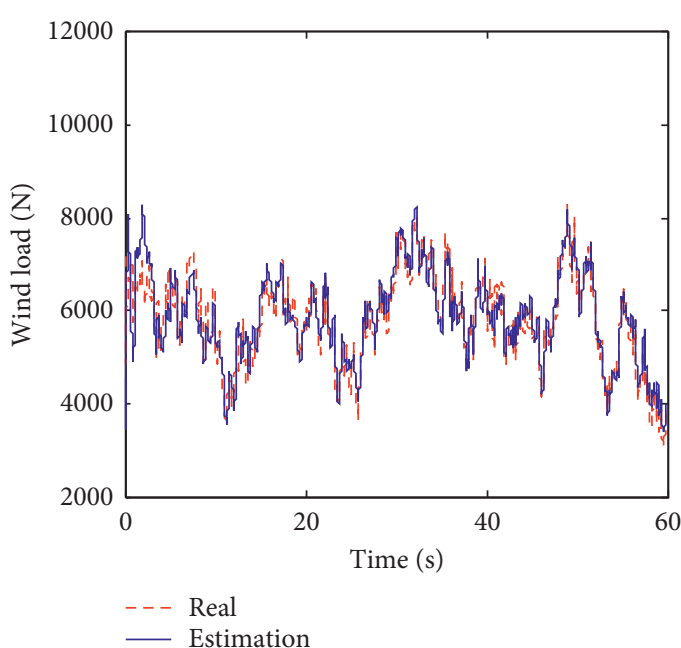

(a)

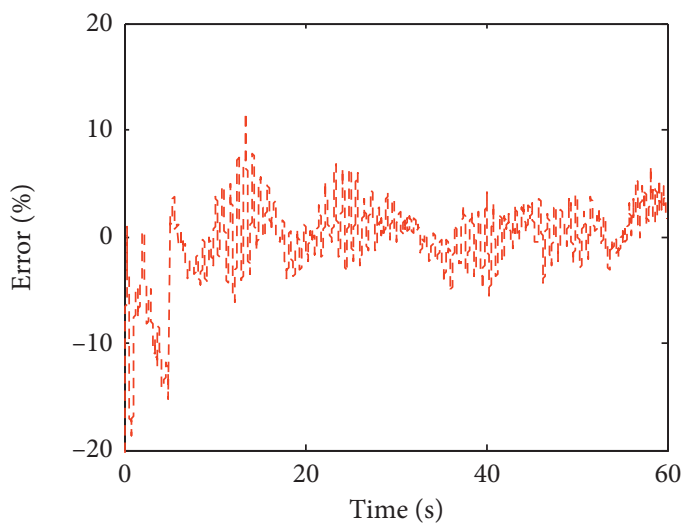

(c)

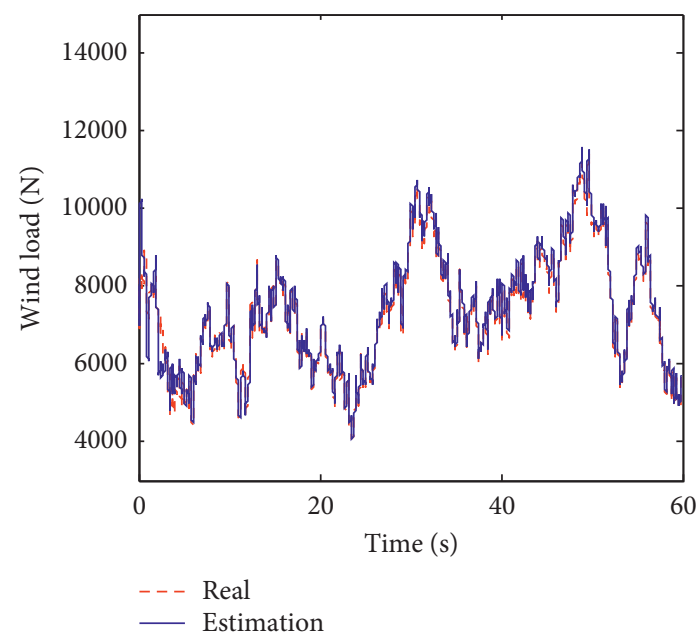

(b)

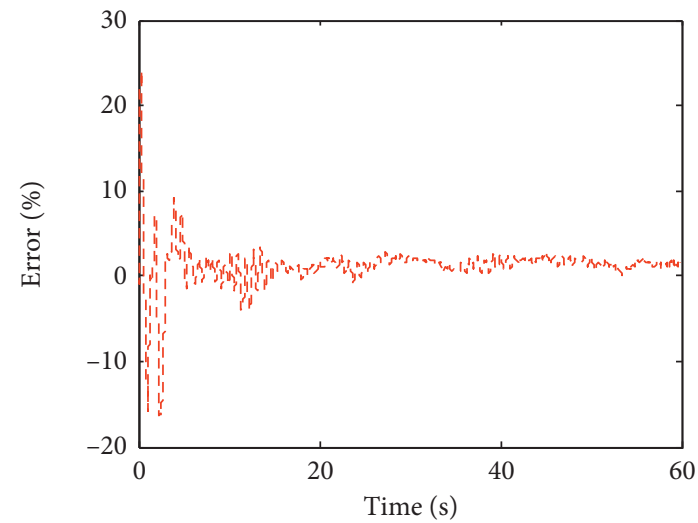

(d)

Figure 5: Comparison of the wind load time histories. Wind load on the (a) fifth floor and (b) tenth floor. Wind load errors on the (c) fifth floor and (d) tenth floor.

TABLE 2: Mean errors and RMS errors for wind load estimation.

\begin{tabular}{lccccc}
\hline Floor number & Mean error (\%) & RMS error (\%) & Floor number & Mean error (\%) & RMS error (\%) \\
\hline 1 & 0.22 & 4.11 & 6 & 4.09 & 3.68 \\
2 & 3.88 & 4.17 & 7 & 3.56 & 3.82 \\
3 & 4.12 & 4.31 & 8 & 3.21 & 3.21 \\
4 & 3.01 & 3.49 & 10 & 1.16 & 2.92 \\
5
\end{tabular}

4.1. Equivalent Model of the Tall Building. For building structures with large degrees-of-freedom, it is complicated or even impossible to estimate the wind load and structural parameters strictly according to the prototype structure. Generally, a simplified equivalent model with less degreesof-freedom is needed in practical analysis. The equivalent model requires that the vibration responses of the two systems are same. This means that the work-energy between the prototype structure and the equivalent structure is equal. Based on the method proposed in [33], the equivalent mass and equivalent stiffness can be obtained as follows:

$$
\begin{aligned}
& M_{\mathrm{e}}=\frac{E\left\{\int_{0}^{H_{i}} m(z) \dot{\mathbf{x}}^{2}(z, t) d z\right\}}{E\left\{\dot{\mathbf{x}}_{0}^{2}+\dot{\mathbf{x}}_{H_{i}}^{2}\right\}}, \\
& K_{\mathrm{e}}=\frac{E\left\{\int_{0}^{H_{i}} k(z) x^{2}(z, t) d z\right\}}{E\left\{x_{0}^{2}+x_{H_{i}}^{2}\right\}},
\end{aligned}
$$

in which $m(z)$ is the mass distribution of the prototype structure, $k(z)$ is the stiffness distribution of the prototype structure, $x(z, t)$ is the displacement of the prototype structure, $M_{\mathrm{e}}$ is the equivalent mass, and $K_{\mathrm{e}}$ is the equivalent stiffness. 


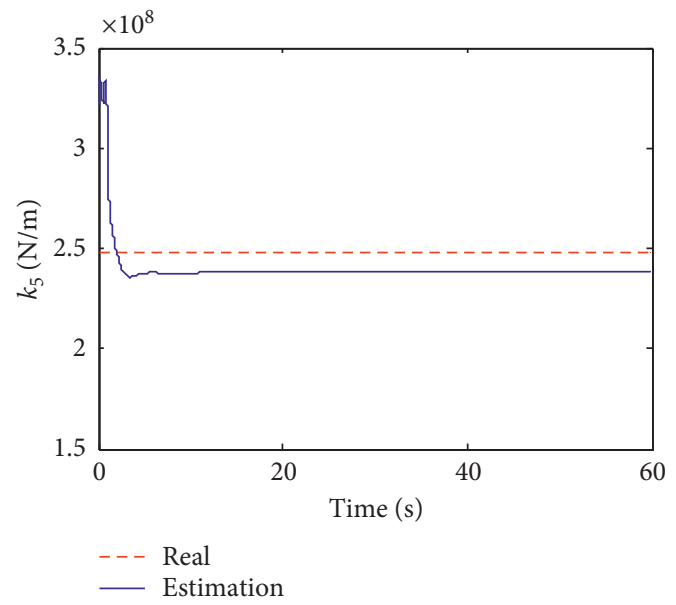

(a)

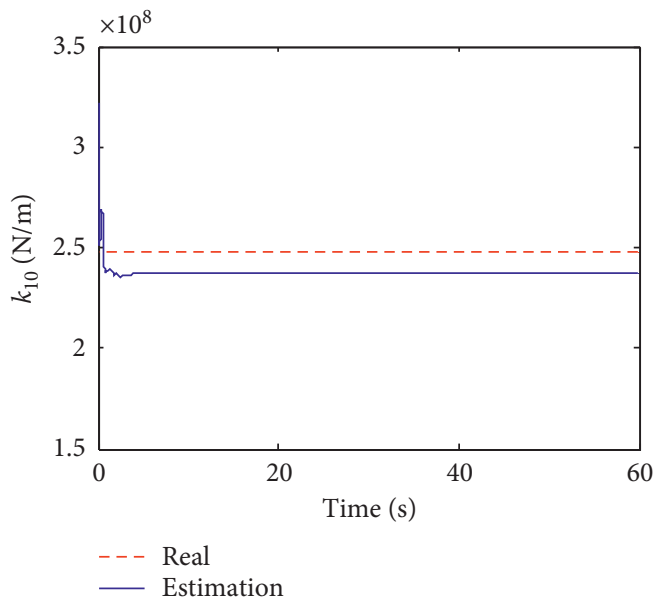

(b)

FIGURE 6: Estimation results of unknown stiffness coefficients on the (a) fifth floor and (b) tenth floor.

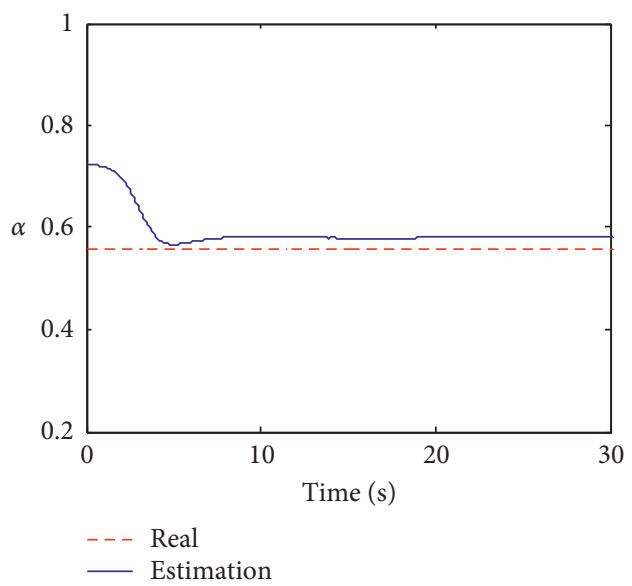

(a)

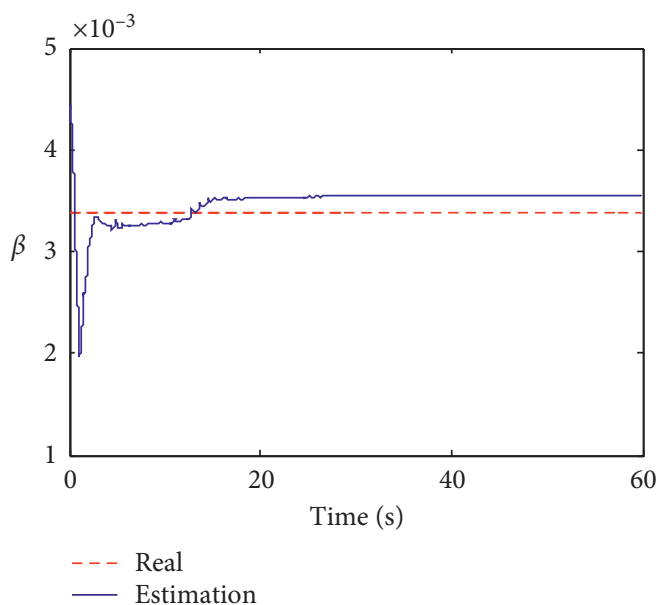

(b)

FIGURE 7: Estimation results of unknown damping coefficients: damping coefficients (a) $\alpha$ and (b) $\beta$.

TABLE 3: Estimation values and errors of structural parameters.

\begin{tabular}{|c|c|c|c|c|c|}
\hline Structural parameter & Estimated value & Error (\%) & Structural parameter & Estimated value & Error (\%) \\
\hline$k_{1}$ & $2.55 \times 10^{8}$ & 3.97 & $k_{7}$ & $2.55 \times 10^{8}$ & 4.08 \\
\hline$k_{2}$ & $2.37 \times 10^{8}$ & 3.44 & $k_{8}$ & $2.55 \times 10^{8}$ & 4.19 \\
\hline$k_{3}$ & $2.35 \times 10^{9}$ & 4.15 & $k_{9}$ & $2.53 \times 10^{8}$ & 3.37 \\
\hline$k_{4}$ & $2.54 \times 10^{8}$ & 3.84 & $k_{10}$ & $2.34 \times 10^{8}$ & 4.30 \\
\hline$k_{5}$ & $2.35 \times 10^{8}$ & 3.96 & $\alpha$ & $5.81 \times 10^{-1}$ & 4.25 \\
\hline$k_{6}$ & $2.35 \times 10^{8}$ & 3.99 & $\beta$ & $3.58 \times 10^{-3}$ & 4.24 \\
\hline
\end{tabular}

Based on the mode decomposition method, the displacement can be represented as follows:

$$
x(z, t)=\sum_{j} Y_{j}(t) \varphi_{j}(z)
$$

where $Y_{j}(t)$ is the $j$-th modal displacement and $\varphi_{j}(z)$ is the $j$-th mode shape vector. For tall building structures, the first mode is taken as the main mode of vibration. Then, the equivalent mass and equivalent stiffness can be calculated as follows: 
TABLE 4: RMS errors of the estimated wind load under different sampling durations.

\begin{tabular}{lcccc}
\hline Floor number & & \multicolumn{3}{c}{ RMS error (\%) } \\
\hline 1 & Duration: $1 \mathrm{~s}$ & Duration: $10 \mathrm{~s}$ & Duration: $30 \mathrm{~s}$ & 4.52 \\
Duration: $60 \mathrm{~s}$ \\
2 & 7.77 & 6.33 & 4.45 & 4.11 \\
3 & 5.86 & 5.68 & 4.45 & 4.31 \\
4 & 5.83 & 5.20 & 3.97 & 3.49 \\
5 & 6.65 & 5.92 & 4.03 & 3.87 \\
6 & 14.23 & 7.68 & 4.58 & 4.55 \\
7 & 7.46 & 5.15 & 3.92 & 3.82 \\
8 & 7.30 & 5.74 & 4.35 & 3.21 \\
9 & 6.23 & 5.41 & 3.34 & 3.30 \\
10 & 7.55 & 6.54 & 3.81 & 2.92 \\
\hline
\end{tabular}

TABLE 5: Structural parameter estimation results under different sampling durations.

\begin{tabular}{|c|c|c|c|c|c|c|c|c|}
\hline \multirow{2}{*}{ Structural parameter } & \multicolumn{2}{|c|}{ Duration: $1 \mathrm{~s}$} & \multicolumn{2}{|c|}{ Duration: $10 \mathrm{~s}$} & \multicolumn{2}{|c|}{ Duration: $30 \mathrm{~s}$} & \multicolumn{2}{|c|}{ Duration: $60 \mathrm{~s}$} \\
\hline & Estimated value & Error (\%) & Estimated value & Error (\%) & Estimated value & Error $(\%)$ & Estimated value & Error (\%) \\
\hline$k_{1}$ & $2.59 \times 10^{8}$ & 5.86 & $2.57 \times 10^{8}$ & 4.98 & $2.55 \times 10^{8}$ & 4.12 & $2.55 \times 10^{8}$ & 3.97 \\
\hline$k_{2}$ & $2.33 \times 10^{8}$ & 4.89 & $2.36 \times 10^{8}$ & 3.55 & $2.37 \times 10^{8}$ & 3.45 & $2.37 \times 10^{8}$ & 3.44 \\
\hline$k_{3}$ & $2.36 \times 10^{8}$ & 3.76 & $2.37 \times 10^{8}$ & 3.39 & $2.35 \times 10^{8}$ & 4.20 & $2.35 \times 10^{8}$ & 4.15 \\
\hline$k_{4}$ & $2.56 \times 10^{8}$ & 4.55 & $2.55 \times 10^{8}$ & 4.14 & $2.55 \times 10^{8}$ & 4.15 & $2.54 \times 10^{8}$ & 3.84 \\
\hline$k_{5}$ & $2.59 \times 10^{8}$ & 5.61 & $2.57 \times 10^{8}$ & 4.84 & $2.35 \times 10^{8}$ & 4.01 & $2.35 \times 10^{8}$ & 3.96 \\
\hline$k_{6}$ & $2.26 \times 10^{8}$ & 7.62 & $2.28 \times 10^{8}$ & 6.99 & $2.35 \times 10^{8}$ & 4.02 & $2.35 \times 10^{8}$ & 3.99 \\
\hline$k_{7}$ & $2.56 \times 10^{8}$ & 4.41 & $2.55 \times 10^{8}$ & 4.08 & $2.55 \times 10^{8}$ & 4.09 & $2.55 \times 10^{8}$ & 4.08 \\
\hline$k_{8}$ & $2.56 \times 10^{8}$ & 4.35 & $2.55 \times 10^{8}$ & 4.21 & $2.55 \times 10^{8}$ & 4.21 & $2.55 \times 10^{8}$ & 4.19 \\
\hline$k_{9}$ & $2.55 \times 10^{8}$ & 4.06 & $2.53 \times 10^{8}$ & 3.36 & $2.53 \times 10^{8}$ & 3.40 & $2.53 \times 10^{8}$ & 3.37 \\
\hline$k_{10}$ & $2.28 \times 10^{8}$ & 6.97 & $2.29 \times 10^{8}$ & 6.53 & $2.34 \times 10^{8}$ & 4.52 & $2.34 \times 10^{8}$ & 4.3 \\
\hline$\alpha$ & 0.740 & 32.78 & 0.575 & 3.28 & 0.581 & 4.66 & 0.581 & 4.25 \\
\hline$\beta$ & 0.00440 & 29.33 & 0.00325 & 4.37 & 0.00348 & 3.49 & 0.00348 & 2.24 \\
\hline
\end{tabular}

TABLE 6: Number of measurements and corresponding locations.

\begin{tabular}{lc}
\hline Number of measurements & Location (floor) \\
\hline 9 & $1,2,3,5,6,7,8,9,10$ \\
8 & $1,3,4,5,6,8,9,10$ \\
7 & $2,3,4,5,7,9,10$ \\
6 & $1,2,4,6,8,10$ \\
5 & $2,4,6,8,10$ \\
4 & $1,4,6,9$ \\
\hline
\end{tabular}

$$
\begin{gathered}
M_{\mathrm{e}}=\frac{\int_{0}^{H_{i}} m(z) \varphi_{i}^{2}(z) d z}{\varphi_{1}^{2}(0)+\varphi_{1}^{2}\left(H_{i}\right)}, \\
K_{\mathrm{e}}=\frac{\int_{0}^{H_{i}} k(z) \varphi_{i}^{2}(z) d z}{\varphi_{1}^{2}(0)+\varphi_{1}^{2}\left(H_{i}\right)} .
\end{gathered}
$$

Table 9 lists the energy contribution $\kappa$ of the first five modal acceleration responses, modal velocity responses, and modal displacement responses, which are calculated according to the following equation:

$$
\kappa=\frac{\sum_{i=1}^{i=m} \sigma_{i}}{\sum_{i=1}^{i=n} \sigma_{i}}, \quad 1 \leq m \leq n,
$$

where $\sigma_{i}$ is the mean squared value of the responses calculated based on proper orthogonal decomposition [34]. It can be seen that energy contribution of the first five modes is over 99\%. Therefore, the simplified equivalent model is chosen as a shear building structure with five degrees-offreedom. Assume that the simplified model quality is concentrated on the 12th, 24th, 36th, 48th, and 58th floors corresponding to the height of $50 \mathrm{~m}, 98 \mathrm{~m}, 146 \mathrm{~m}, 194 \mathrm{~m}$, and $234 \mathrm{~m}$, respectively. The equivalent mass coefficients and stiffness coefficients are calculated based on Equations (55) and (56), respectively, which are shown in Table 10. Table 11 gives the first five natural frequencies of the prototype structure and the equivalent model. It can be found that the relative errors of the first three natural frequencies are under $5 \%$. Figure 14 shows the comparison of the first two mode shapes between the prototype structure and the equivalent structure. It can be found that the mode shapes of the equivalent structure are consistent with that of the prototype structure. The damping of this structure is considered as Rayleigh damping with damping ratio corresponding to the first two modes of vibration being $5 \%$.

4.2. Wind Load and Structural Parameters Estimation. The wind-induced responses of the tall building cannot be measured directly from the pressure measurement on a rigid model in the wind tunnel test. Hence, wind-induced responses including displacement, velocity, and acceleration responses are calculated based on the wind tunnel test results and the structural dynamic properties of the prototype building structure using the Newmark- $\beta$ method. In order to 


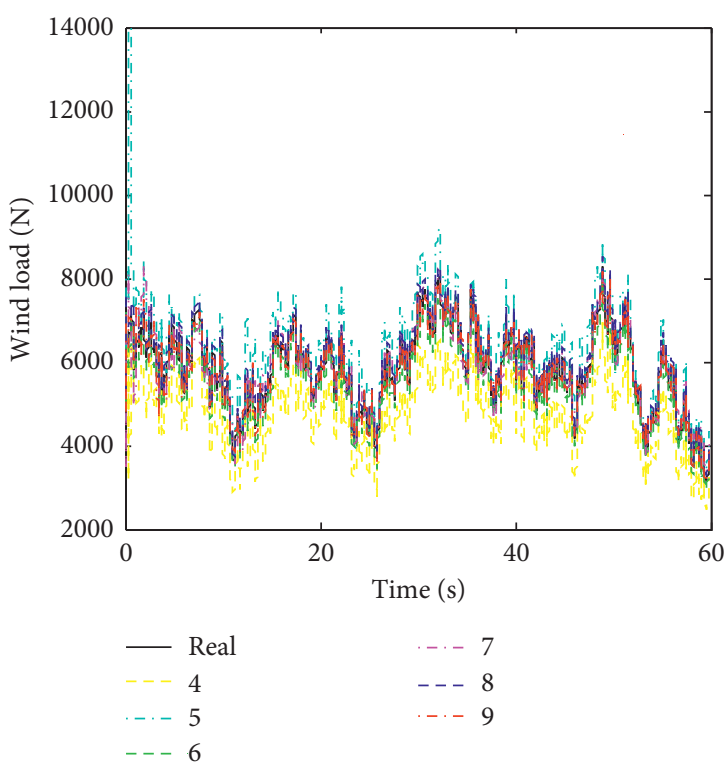

(a)

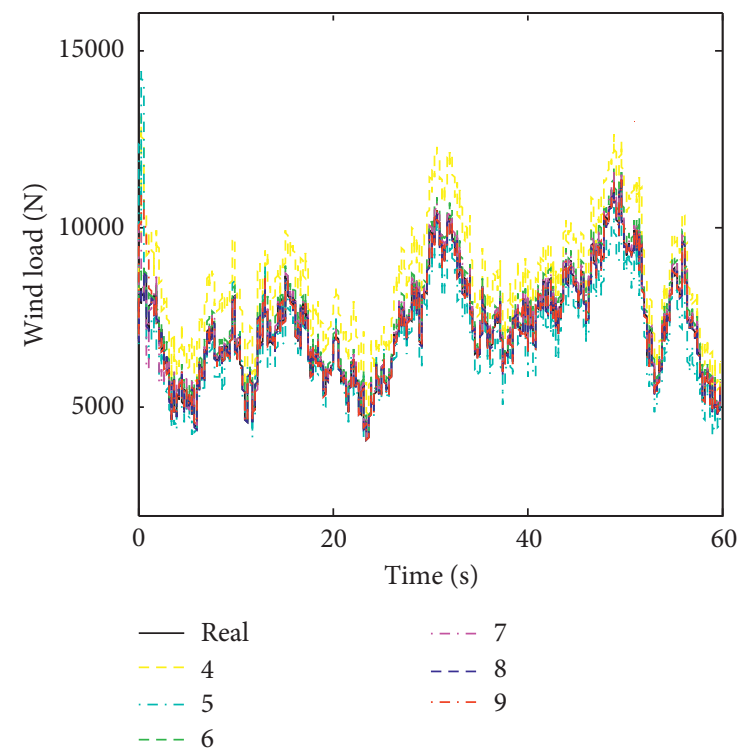

(b)

Figure 8: Time histories of the estimated wind load for different numbers of measurements on the (a) fifth floor and (b) tenth floor.

TABLE 7: RMS errors of wind load for different numbers of measurements.

\begin{tabular}{|c|c|c|c|c|c|c|}
\hline Floor number & $\begin{array}{c}\text { Nine } \\
\text { measurements }\end{array}$ & Eight measurements & Seven measurements & Six measurements & Five measurements & Four measurements \\
\hline 1 & 2.43 & 3.47 & 4.11 & 4.77 & 6.27 & 9.29 \\
\hline 2 & 2.4 & 3.06 & 4.17 & 4.71 & 5.14 & 10.6 \\
\hline 3 & 2.06 & 3.24 & 4.31 & 4.7 & 6.38 & 8.12 \\
\hline 4 & 2.34 & 3.01 & 3.49 & 4.38 & 6.09 & 10.78 \\
\hline 5 & 2.43 & 3.15 & 3.87 & 4.51 & 7.08 & 9.2 \\
\hline 6 & 2.98 & 3.42 & 4.56 & 5.33 & 5.59 & 8.23 \\
\hline 7 & 2.49 & 3.3 & 3.82 & 4.58 & 6.03 & 10.06 \\
\hline 8 & 2.24 & 3.45 & 4.21 & 4.77 & 5.77 & 9.2 \\
\hline 9 & 0.81 & 2.31 & 3.3 & 4.95 & 6.30 & 8.05 \\
\hline 10 & 1.1 & 2.42 & 2.92 & 3.48 & 5.94 & 9.25 \\
\hline
\end{tabular}

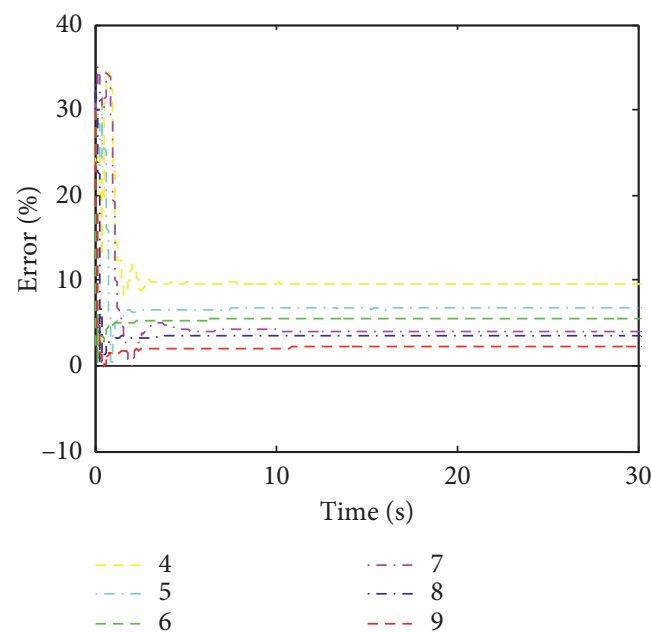

(a)

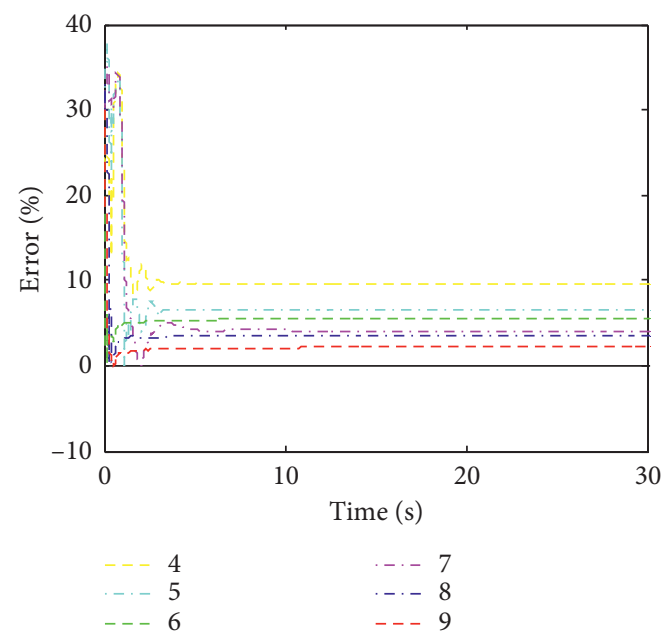

(b)

FiguRE 9: Estimated stiffness coefficients for different numbers of measurements on the (a) fifth floor and (b) tenth floor. 


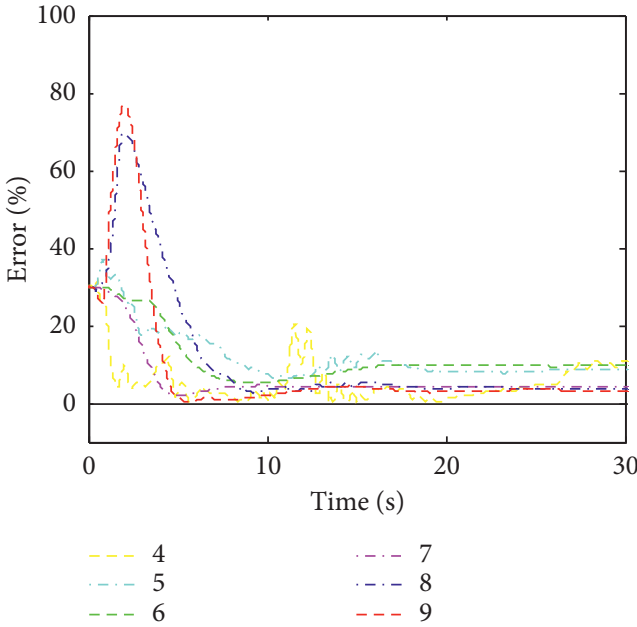

(a)

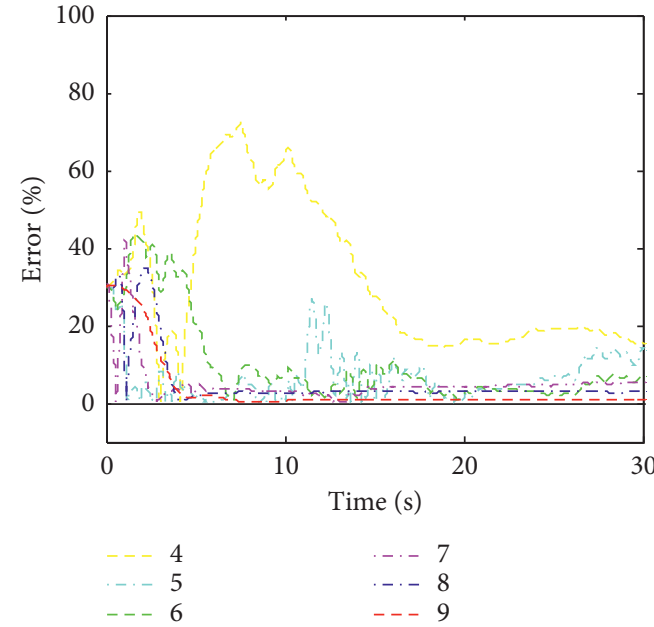

(b)

Figure 10: Estimated damping coefficients for different numbers of measurements: damping coefficients (a) $\alpha$ and (b) $\beta$.

TABLE 8: Estimation of structural parameters under different numbers of measurements.

\begin{tabular}{|c|c|c|c|c|c|c|c|c|c|c|c|c|}
\hline \multirow{2}{*}{$\begin{array}{l}\text { Structural } \\
\text { parameter }\end{array}$} & \multicolumn{2}{|c|}{$\begin{array}{c}\text { Nine } \\
\text { measurements }\end{array}$} & \multicolumn{2}{|c|}{$\begin{array}{c}\text { Eight } \\
\text { measurements }\end{array}$} & \multicolumn{2}{|c|}{$\begin{array}{c}\text { Seven } \\
\text { measurements }\end{array}$} & \multicolumn{2}{|c|}{ Six measurements } & \multicolumn{2}{|c|}{$\begin{array}{c}\text { Five } \\
\text { measurements }\end{array}$} & \multicolumn{2}{|c|}{$\begin{array}{c}\text { Four } \\
\text { measurements }\end{array}$} \\
\hline & $\begin{array}{l}\text { Value } \\
\left(\times 10^{8}\right)\end{array}$ & $\begin{array}{c}\text { Error } \\
(\%)\end{array}$ & $\begin{array}{l}\text { Value } \\
\left(\times 10^{8}\right)\end{array}$ & $\begin{array}{c}\text { Error } \\
(\%)\end{array}$ & $\begin{array}{l}\text { Value } \\
\left(\times 10^{8}\right)\end{array}$ & $\begin{array}{c}\text { Error } \\
(\%)\end{array}$ & $\begin{array}{l}\text { Value } \\
\left(\times 10^{8}\right)\end{array}$ & $\begin{array}{l}\text { Error } \\
(\%)\end{array}$ & $\begin{array}{l}\text { Value } \\
\left(\times 10^{8}\right)\end{array}$ & $\begin{array}{c}\text { Error } \\
(\%)\end{array}$ & $\begin{array}{l}\text { Value } \\
\left(\times 10^{8}\right)\end{array}$ & $\begin{array}{c}\text { Error } \\
(\%)\end{array}$ \\
\hline$k_{1}$ & 2.52 & 2.81 & 2.37 & 3.38 & 2.55 & 3.97 & 2.35 & 4.12 & 2.61 & 6.52 & 2.68 & 9.51 \\
\hline$k_{2}$ & 2.39 & 2.56 & 2.52 & 2.88 & 2.37 & 3.44 & 2.55 & 4.02 & 2.60 & 6.28 & 2.68 & 9.48 \\
\hline$k_{3}$ & 2.40 & 2.03 & 2.37 & 3.12 & 2.35 & 4.15 & 2.34 & 4.31 & 2.58 & 5.45 & 2.21 & 9.62 \\
\hline$k_{4}$ & 2.40 & 1.97 & 2.53 & 3.24 & 2.54 & 3.84 & 2.30 & 5.98 & 2.61 & 6.44 & 2.22 & 9.26 \\
\hline$k_{5}$ & 2.51 & 2.35 & 2.53 & 3.44 & 2.35 & 3.96 & 2.59 & 5.65 & 2.28 & 6.74 & 2.69 & 9.64 \\
\hline$k_{6}$ & 2.51 & 2.26 & 2.38 & 2.76 & 2.35 & 3.99 & 2.57 & 5.07 & 2.29 & 6.39 & 2.70 & 10.08 \\
\hline$k_{7}$ & 2.38 & 2.86 & 2.37 & 3.42 & 2.55 & 4.08 & 2.57 & 4.94 & 2.30 & 6.27 & 2.68 & 9.25 \\
\hline$k_{8}$ & 2.39 & 2.28 & 2.52 & 2.98 & 2.55 & 4.19 & 2.32 & 5.43 & 2.62 & 6.74 & 2.71 & 10.46 \\
\hline$k_{9}$ & 2.49 & 1.50 & 2.51 & 2.49 & 2.53 & 3.37 & 2.55 & 4.25 & 2.29 & 6.73 & 2.67 & 9.18 \\
\hline$k_{10}$ & 2.50 & 2.12 & 2.53 & 3.40 & 2.34 & 4.30 & 2.58 & 5.43 & 2.29 & 6.62 & 2.69 & 9.61 \\
\hline$A \times 10^{8}$ & 0.577 & 3.63 & 0.581 & 3.71 & 0.581 & 4.25 & 0.612 & 9.83 & 0.592 & 6.27 & 0.606 & 8.71 \\
\hline$\beta \times 10^{8}$ & 0.00342 & 0.76 & 0.0035 & 2.8 & 0.00348 & 2.24 & 0.00358 & 5.33 & 0.0038 & 11.76 & 0.00384 & 13.01 \\
\hline
\end{tabular}

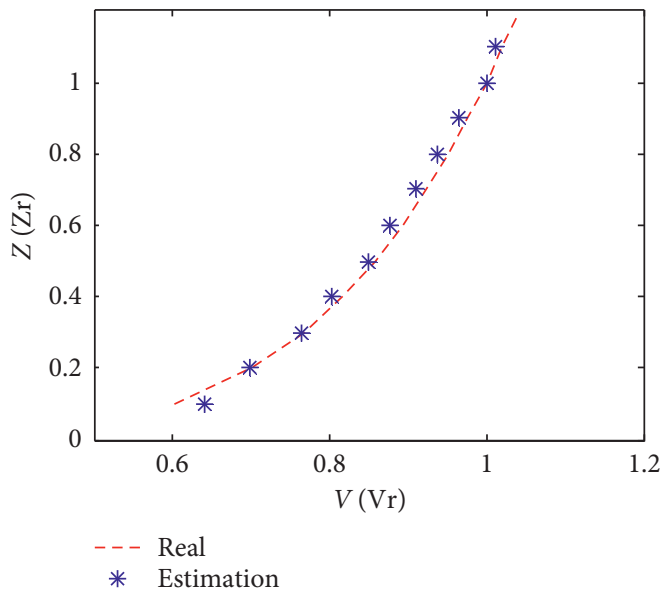

(a)

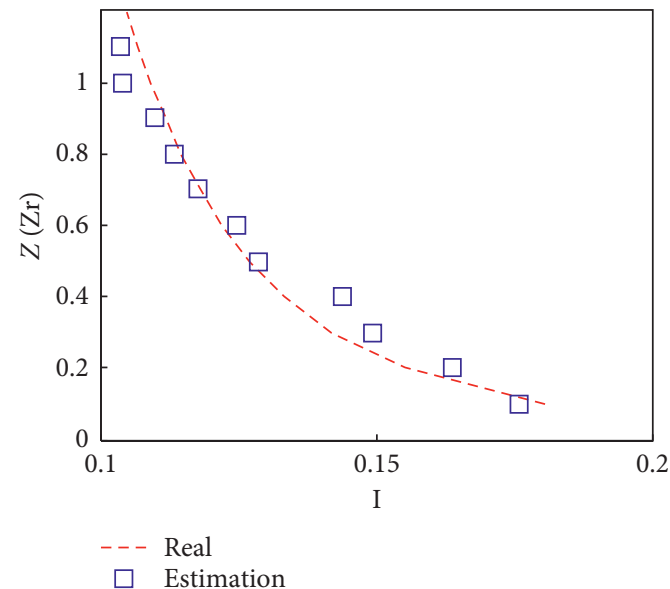

(b)

Figure 11: Mean wind speed and turbulence intensity profiles: (a) mean wind speed; (b) turbulence intensity. 


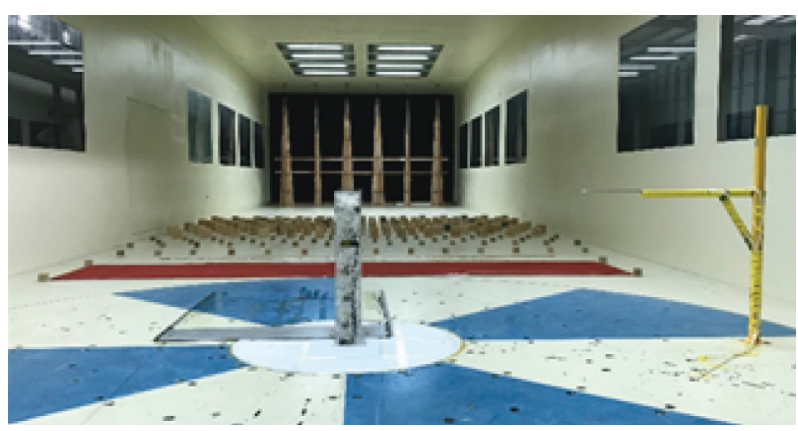

FIGURE 12: Wind tunnel test model.

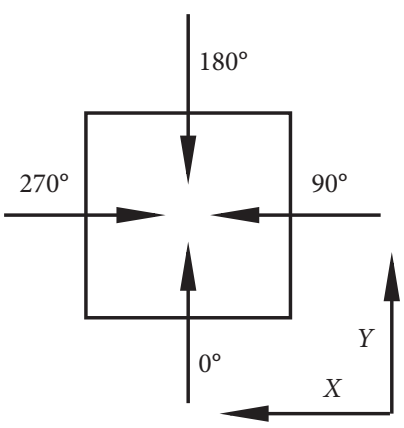

Figure 13: Coordinate system.

TABLE 9: Energy contribution ratio of the first five modal responses.

\begin{tabular}{lcccrr}
\hline Number of modes & 1 & 2 & 3 & 4 & 5 \\
\hline Displacement & 99.458 & 99.963 & 99.994 & 99.999 & 99.999 \\
Velocity & 98.068 & 99.673 & 99.898 & 99.963 & 99.989 \\
Acceleration & 85.276 & 94.096 & 96.825 & 98.396 & 99.369 \\
\hline
\end{tabular}

TABLE 10: Equivalent mass and stiffness of the equivalent model.

\begin{tabular}{lccccc}
\hline Floor number & 1 & 2 & 3 & 4 & 5 \\
\hline$M_{\mathrm{e}}$ & $3.62 \times 10^{7}$ & $2.38 \times 10^{7}$ & $2.30 \times 10^{7}$ & $2.11 \times 10^{7}$ & $1.16 \times 10^{7}$ \\
$K_{\mathrm{e}}$ & $9.53 \times 10^{8}$ & $2.52 \times 10^{8}$ & $2.30 \times 10^{8}$ & $2.04 \times 10^{8}$ & $1.74 \times 10^{8}$ \\
\hline
\end{tabular}

TABLE 11: Comparison of the first five natural frequencies between the prototype model and the equivalent model.

\begin{tabular}{lccccc}
\hline Modal order & 1 & 2 & 3 & 4 & 5 \\
\hline Real value & 0.19 & 0.49 & 0.77 & 1.07 & 1.35 \\
Simplified model & 0.19 & 0.51 & 0.76 & 0.90 & 1.00 \\
Error (\%) & 2.48 & 4.16 & 2.34 & 15.50 & 26.10 \\
\hline
\end{tabular}

validate the feasibility of the proposed method, only three sets of measurements including structural interstory displacement responses and acceleration responses on the 12th, 36th, and 58th floors are taken as the "measurements." The unknown parameters are five stiffness coefficients and two Rayleigh damping coefficients of the equivalent model. The unknown excitations are equivalent wind load on the equivalent model. The initial value of the state vector is $\mathbf{Z}_{1 \mid 0}=\left[\begin{array}{llll}0_{1 \times 10} & 1.3 k & 1.3 \alpha & 1.3 \beta\end{array}\right]$. The initial error covariance matrix is $\mathbf{P}_{1 \mid 0}^{\mathrm{Z}}=\operatorname{diag}\left([1,1, \ldots, 1]_{1 \times 10}\left(10^{25}, 10^{25}, \ldots\right.\right.$, $\left.\left.10^{25}\right)_{1 \times 10} 10^{3} 10^{1}\right)$. The covariance matrices of process noise and measurement noise are $10^{-2}$ and $10^{-1}$, respectively.

Figures 15 and 16 show the estimation results of structural displacement responses and velocity responses on the 24th and 58th floors, respectively. It can be found that the time histories of the estimated responses match very well with the exact responses. Meanwhile, the power spectrum of the estimated responses is found to agree well with those of the exact responses except slight differences in high frequency components $(>0.8 \mathrm{~Hz})$ of the responses on the 24 th floor. This is mainly because (1) there is no measurement information on the 24th floor, and the estimation results on the 24th floor is obtained from modal transformation and (2) the errors of the modal information between the equivalent model and prototype model are large in higher modes (i.e., the fourth and fifth modes). 


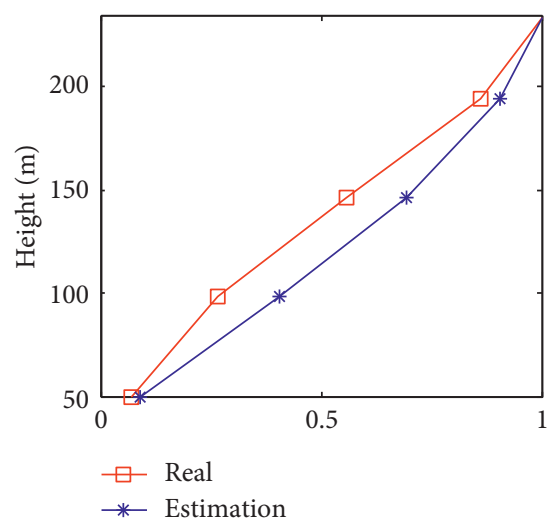

(a)

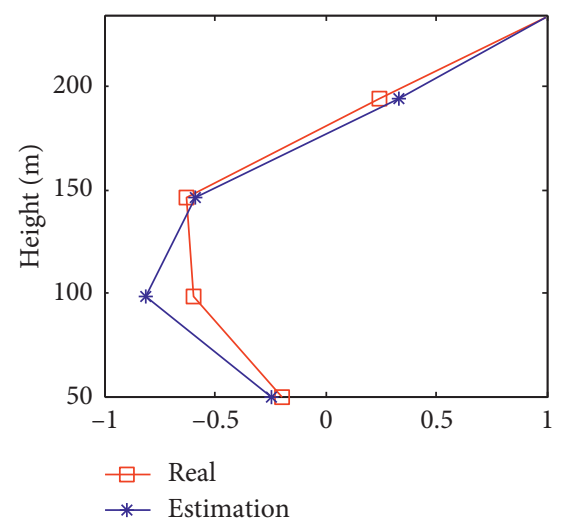

(b)

FIGURE 14: Comparison of the mode shape: (a) the first mode shape; (b) the second mode shape.

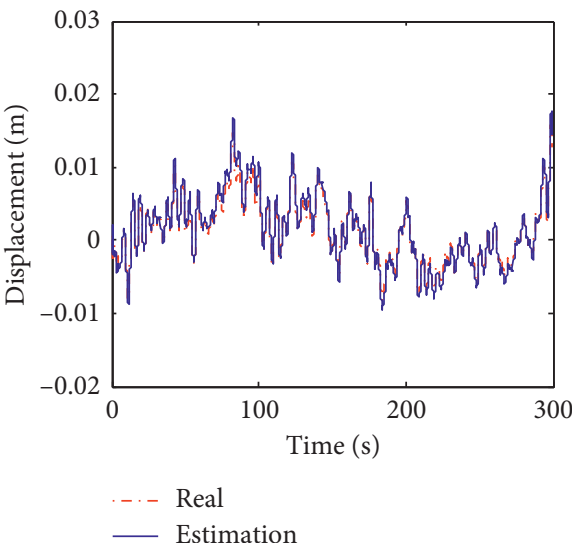

(a)

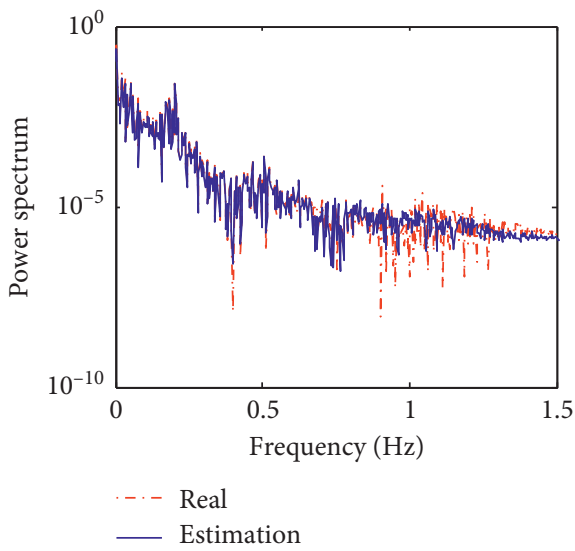

(c)

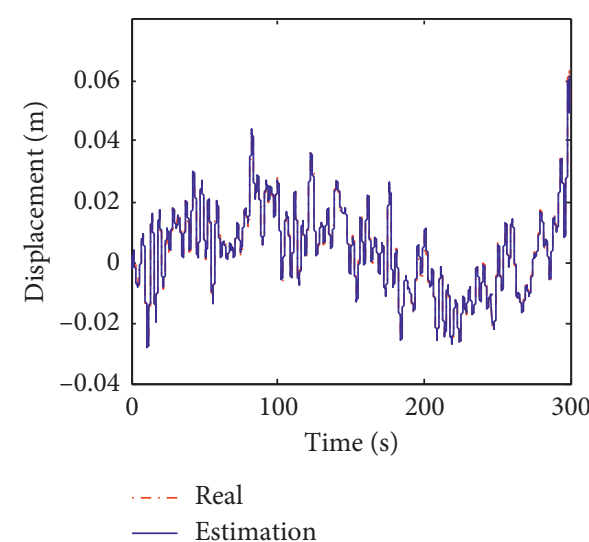

(b)

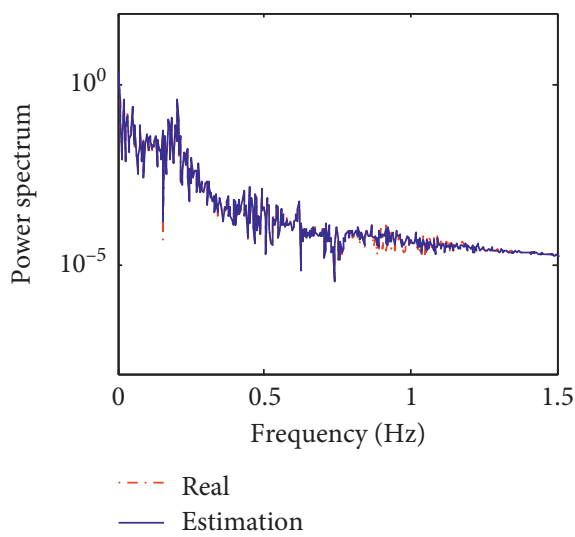

(d)

Figure 15: Comparison of the structural displacement responses in direction $X$ under wind direction of $180^{\circ}$. Time history on the (a) 24 th floor and (b) 58th floor. Power spectrum on the (c) 24th floor and (d) 58th floor.

Displayed in Figure 17 is the comparison of the time histories of the equivalent wind load between the exact values and estimated values on the 24th floor and 58th floor. It can be observed that the estimated curves agree very well with the exact ones. The estimation errors of the equivalent wind load are listed in Table 12. From Table 12, the maximum mean error and RMS error of the identified wind load are $4.95 \%$ and $5.89 \%$. Figure 18 shows the estimation results of the equivalent stiffness coefficients. It indicates that the stiffness coefficients can converge to the real value within $5 \mathrm{~s}$. The estimation results of damping coefficients are shown in Figure 19, and it can be found that the damping 


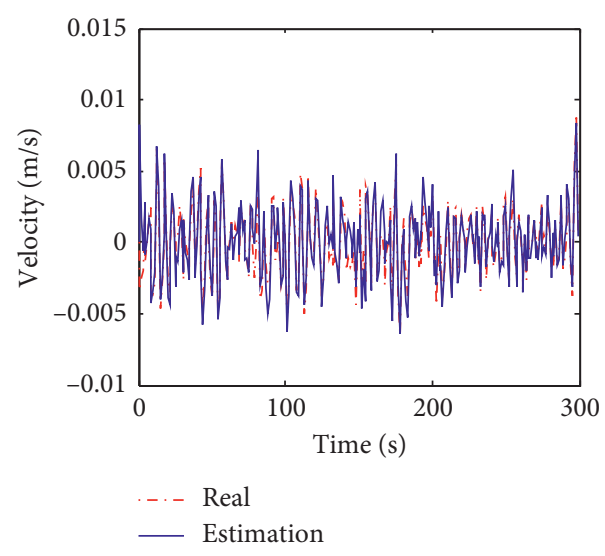

(a)

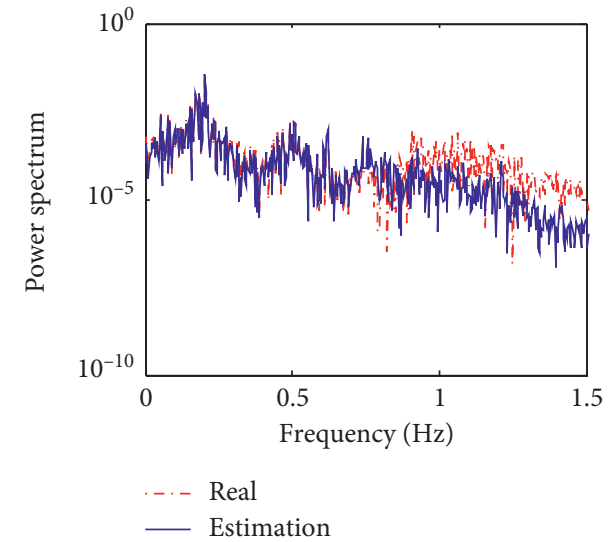

(c)

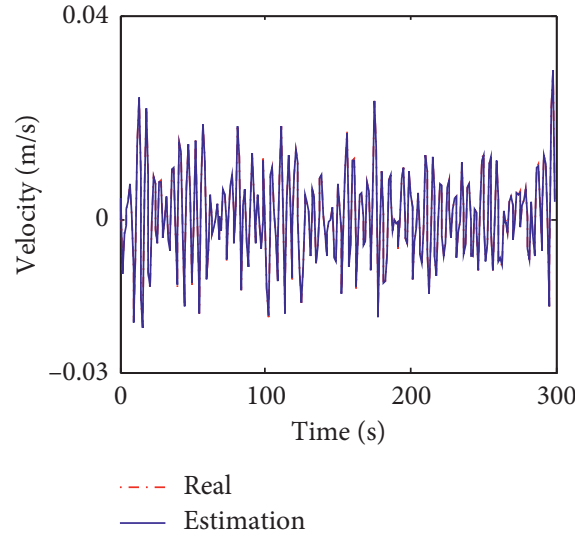

(b)

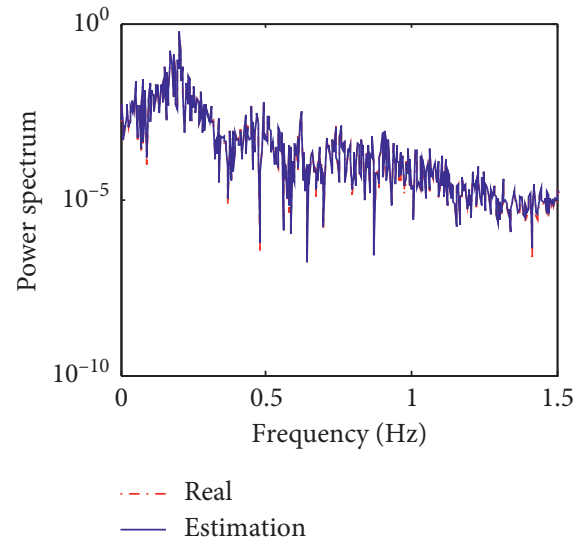

(d)

FIGURE 16: Comparison of the structural velocity responses in direction $X$ under wind direction of $180^{\circ}$. Time history on the (a) 24 th floor and (b) 58th floor. Power spectrum on the (c) 24th floor and (d) 58th floor.

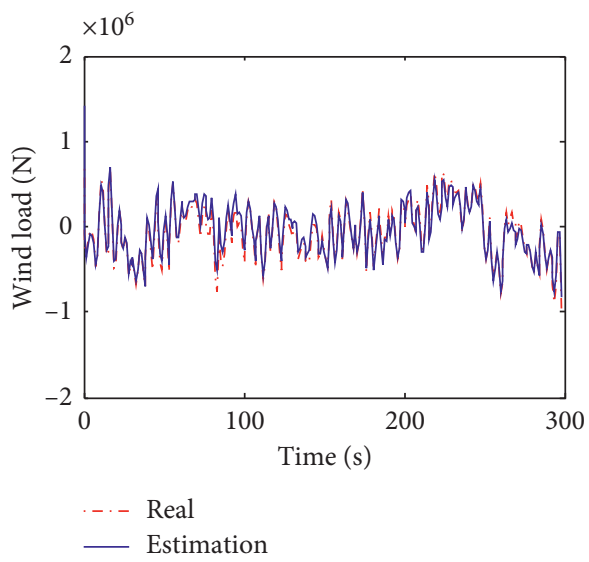

(a)

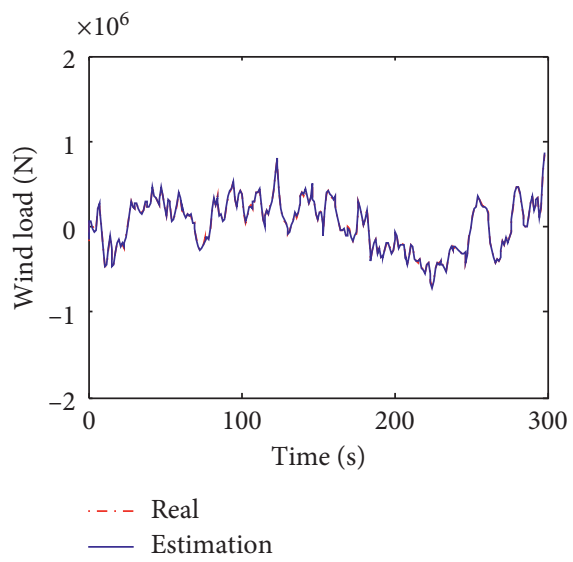

(b)

FIGURE 17: Comparison of the equivalent wind load time histories in direction $X$ under wind direction of $180^{\circ}$ on the (a) 24 th floor and (b) 58 th floor.

coefficients can converge to the real value within about $10 \mathrm{~s}$. The estimated values and errors of structural parameters are given in Table 13. The errors of the stiffness coefficient are less than $5 \%$ except that on the 12 th floor. The errors of the damping coefficient $\alpha$ and $\beta$ are $3.8 \%$ and $2.11 \%$, respectively. The comparison results indicate that the inverse method presented in this study is applicable to the practical engineering. 
TABLE 12: Mean errors and RMS errors for wind load estimation.

\begin{tabular}{lcccrr}
\hline Floor number & 12 & 24 & 36 & 48 & 58 \\
\hline Mean value & 4.95 & 4.59 & -4.87 & 4.29 & 4.93 \\
RMS & 1.63 & 3.85 & 5.27 & 5.55 & 5.89 \\
\hline
\end{tabular}

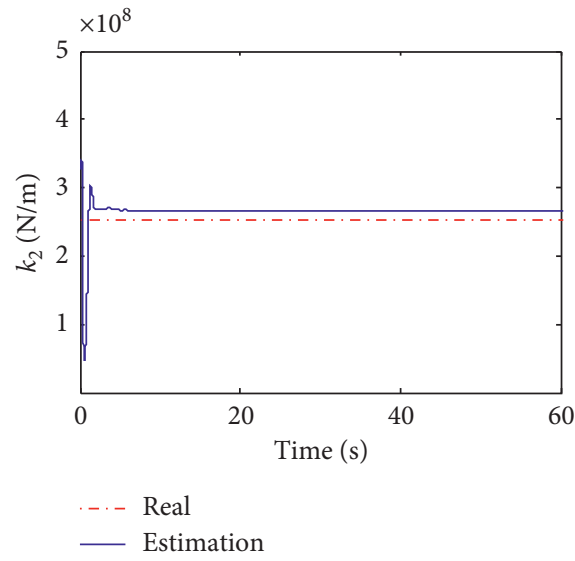

(a)

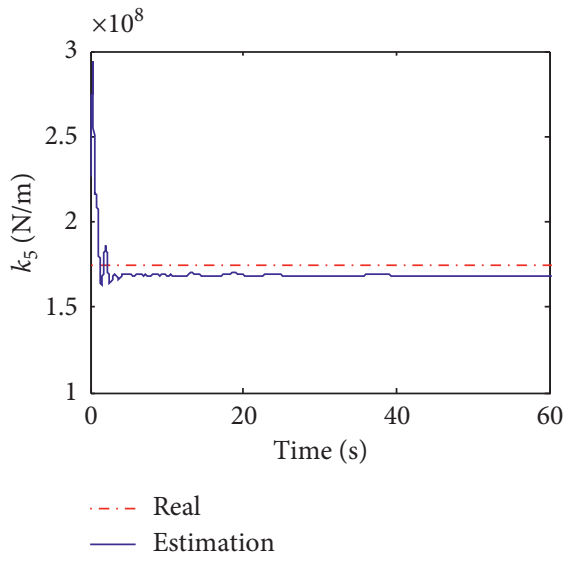

(b)

FIGURE 18: Estimation results of the equivalent stiffness coefficients.

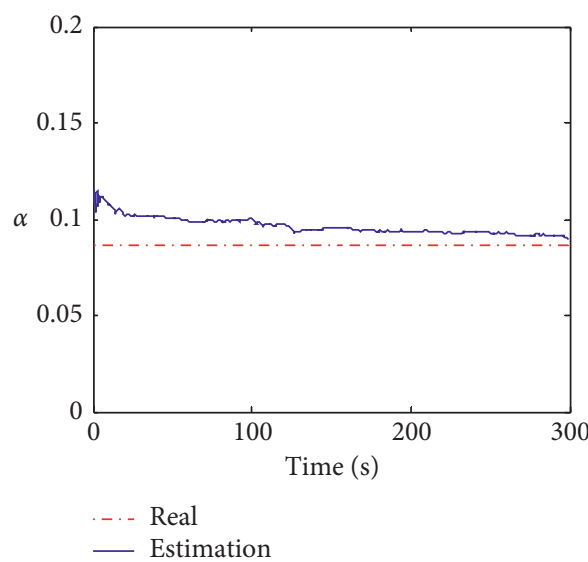

(a)

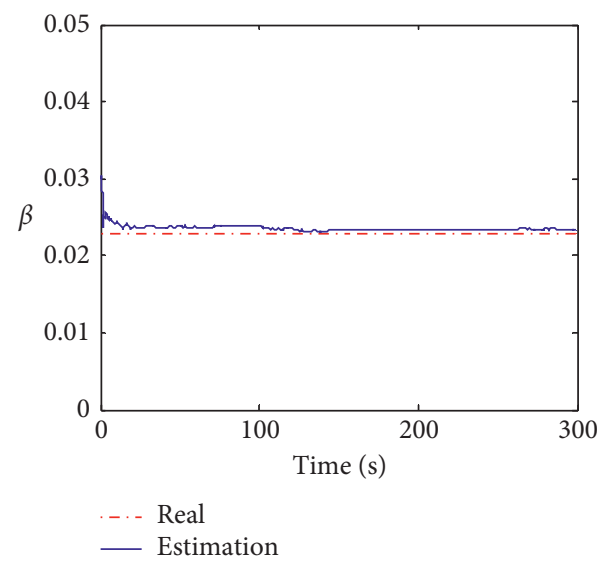

(b)

Figure 19: Estimation results of damping coefficients.

TABLE 13: Estimation values and errors of structural parameters.

\begin{tabular}{lccc}
\hline Structural parameter & True value & Estimated value & Errors (\%) \\
\hline$k_{1}$ & $9.53 \times 10^{8}$ & $9.02 \times 10^{8}$ & 5.40 \\
$k_{2}$ & $2.52 \times 10^{8}$ & $2.62 \times 10^{8}$ & 4.25 \\
$k_{3}$ & $2.30 \times 10^{8}$ & $2.20 \times 10^{8}$ & 4.41 \\
$k_{4}$ & $2.04 \times 10^{8}$ & $1.94 \times 10^{8}$ & 4.81 \\
$k_{5}$ & $1.74 \times 10^{8}$ & $1.66 \times 10^{8}$ & 4.52 \\
$\alpha$ & 0.086 & 0.0898 & 3.80 \\
$\beta$ & 0.023 & 0.0234 & 2.11 \\
\hline
\end{tabular}

\section{Conclusion}

In this paper, a time domain joint state/parameter/wind load estimation method from incomplete measurements is proposed based on modal extended unbiased minimum variance estimation. The recursive procedure includes four parts: time update, modal wind load estimation, measurement update, and coordinate transformation. The measurement responses include the interstory displacement and 
acceleration responses on partial floors. The estimation quality of the proposed method is numerically validated by simultaneously identifying the structural state, parameters, and wind load of a ten-story shear building structure from incomplete measurements. The effects of crucial factors, including sampling duration and the number of measurements on the convergence and accuracy of the proposed method, are discussed. Moreover, a synchronous multipressure scanning system wind tunnel test on a $234 \mathrm{~m}$ tall building structure is used to demonstrate the proposed approach for real structure. A simplified equivalent model with five degrees-of-freedom is derived for experimental validation. Results indicate that the proposed method shows much potential as an alternative way for simultaneously identify the unknown structural parameters, wind load, and wind-induced responses from incomplete measurements.

\section{Data Availability}

The data used to support the findings of this study are available from the corresponding author upon request.

\section{Conflicts of Interest}

The authors declare that there are no conflicts of interest regarding the publication of this article.

\section{Acknowledgments}

This work was supported by the National Nature Science Foundation of China (Grant no. 51608153) and Shenzhen Knowledge Innovation Programme (Grant nos. JCYJ20170413105418298, JCYJ20180306171737796, and JCYJ20170811153857358).

\section{References}

[1] Y. C. He and Q. Li, "Dynamic responses of a 492 m-high tall building with active tuned mass damping system during a typhoon," Structural Control and Health Monitoring, vol. 21, pp. 705-720, 2014.

[2] Q. S. Li, L.-H. Zhi, A. Y. Tuan, C.-S. Kao, S.-C. Su, and C.-F. Wu, "Dynamic behavior of Taipei 101 tower: field measurement and numerical analysis," Journal of Structural Engineering, vol. 137, no. 1, pp. 143-155, 2011.

[3] P. Mendis, T. Ngo, N. Haritos, A. Hira, B. Samali, and J. Cheung, "Wind loading on tall buildings," Electronic Journal of Structural Engineering, vol. 7, pp. 41-54, 2007.

[4] E. Simiu and R. H. Scanlan, Wind Effects on Structures: Fundamentals and Applications to Design, John Wiley, Hoboken, NJ, USA, 1996.

[5] Y. Zhou, T. Kijewski, and A. Kareem, "Along-wind load effects on tall buildings: comparative study of major international codes and standards," journal of Structural Engineering, vol. 128, no. 6, pp. 788-796, 2002.

[6] S. Huang, Q. S. Li, and S. Xu, "Numerical evaluation of wind effects on a tall steel building by CFD," Steel Construction, vol. 63, no. 5, pp. 612-627, 2008.

[7] Q. S. Li, J. Y. Fu, Y. Q. Xiao et al., "Wind tunnel and full-scale study of wind effects on China's tallest building," Engineering Structures, vol. 28, no. 12, pp. 1745-1758, 2006.
[8] T. Uhl, "The inverse identification problem and its technical application," Archive of Applied Mechanics, vol. 77, no. 5, pp. 325-337, 2007.

[9] G. Desanghere, "Indirect identification of excitation forces by modal coordinate transformation," in Proceedings of the $3 \mathrm{rd}$ International Modal Analysis Conference, Orlando, FL, USA, January 1985.

[10] Y.-R. Kim and K.-J. Kim, "Indirect input identification by modal filter technique," Mechanical Systems and Signal Processing, vol. 13, no. 6, pp. 893-910, 1999.

[11] S. S. Law, J. Q. Bu, and X. Q. Zhu, "Time-varying wind load identification from structural responses," Engineering Structures, vol. 27, no. 10, pp. 1586-1598, 2005.

[12] Z. R. Lu and S. S. Law, "Force identification based on sensitivity in time domain," Journal of Engineering Mechanics, vol. 132, no. 10, pp. 1050-1056, 2006.

[13] Y. Liu and W. S. Shepard, "Dynamic force identification based on enhanced least squares and total least-squares schemes in the frequency domain," Journal of Sound \& Vibration, vol. 282, no. 1-2, pp. 37-60, 2005.

[14] J.-J. Liu, C.-K. Ma, I.-C. Kung, and D.-C. Lin, "Input force estimation of a cantilever plate by using a system identification technique," Computer Methods in Applied Mechanics and Engineering, vol. 190, no. 11-12, pp.1309-1322, 2000 .

[15] C.-K. Ma, P.-C. Tuan, D.-C. Lin, and C.-S. Liu, "A study of an inverse method for the estimation of impulsive loads," International Journal of Systems Science, vol. 29, no. 6, pp. 663-672, 1998.

[16] J.-s. Hwang, A. Kareem, and W.-j. Kim, "Estimation of modal loads using structural response," Journal of Sound and Vibration, vol. 326, no. 3-5, pp. 522-539, 2009.

[17] J.-S. Hwang, A. Kareem, and H. Kim, "Wind load identification using wind tunnel test data by inverse analysis," Journal of Wind Engineering and Industrial Aerodynamics, vol. 99, no. 1, pp. 18-26, 2011.

[18] L. H. Zhi, M. X. Fang, and Q. S. Li, "Estimation of wind loads on a tall building by an inverse method," Structural Control \& Health Monitoring, vol. 24, no. 4, p. e1908, 2017.

[19] L. Zhi, Q. S. Li, M. Fang, and J. Yi, "Identification of wind loads on super tall buildings using kalman filtering-based inverse method," Journal of Structural Engineering, vol. 143, no. 4, article 06016004, 2016.

[20] S. Gillijns and B. De Moor, "Unbiased minimum-variance input and state estimation for linear discrete-time systems with direct feedthrough," Automatica, vol. 43, no. 5, pp. 934-937, 2007.

[21] E. Lourens, C. Papadimitriou, S. Gillijns, E. Reynders, G. De Roeck, and G. Lombaert, "Joint input-response estimation for structural systems based on reduced-order models and vibration data from a limited number of sensors," Mechanical Systems and Signal Processing, vol. 29, pp. 310-327, 2012.

[22] H. Xue, K. Lin, Y. Luo, and H. Liu, "Time-varying wind load identification based on minimum-variance unbiased estimation," Shock and Vibration, vol. 2017, pp. 1-15, 2017.

[23] Z. Wan, T. Wang, L. Li, and Z. Xu, "A novel coupled state/ input/parameter identification method for linear structural systems," Shock and Vibration, vol. 2018, Article ID 7691721, 15 pages, 2018.

[24] W. Song, "Generalized minimum variance unbiased joint input-state estimation and its unscented scheme for dynamic systems with direct feedthrough," Mechanical Systems and Signal Processing, vol. 99, pp. 886-920, 2018. 
[25] E. J. Kuhar and C. V. Stahle, "Dynamic transformation method for modal synthesis," AIAA Journal, vol. 12, no. 5, pp. 672-678, 1973.

[26] L. Liu, W. Hua, and Y. Lei, "Real-time simultaneous identification of structural systems and unknown inputs without collocated acceleration measurements based on MEKF-UI," Measurement, vol. 122, pp. 545-553, 2018.

[27] K. F. Alvin, "Efficient computation of eigenvector sensitivities for structural dynamics via conjugate gradients," in Proceedings of the 16th International Modal Analysis Conference, pp. 652-659, Santa Barabara, CA, USA, February 1998.

[28] B. P. Wang, "Improved approximate methods for computing eigenvector derivatives in structural dynamics," AIAA Journal, vol. 29, no. 6, pp. 1018-1020, 1991.

[29] N. P. Jones, T. Shi, J. Hugh Ellis, and R. H. Scanlan, "Systemidentification procedure for system and input parameters in ambient vibration surveys," Journal of Wind Engineering and Industrial Aerodynamics, vol. 54-55, pp. 91-99, 1995.

[30] C. R. Rao, Linear Statistical Inference and its Applications, Wiley, Hoboken, NJ, USA, 1973.

[31] P. K. Kitanidis, "Unbiased minimum-variance linear state estimation," Automatica, vol. 23, no. 6, pp. 775-778, 1987.

[32] B. Gerges, Load Code for the Design of Building Structures, China Architecture \& Building Press, Beijing, China, 2012.

[33] Z. Xiangting, "Study of random vinration of major engineering structure for equivalent-lumped system based on work-enrygu principle," Shock and Vibration, vol. 2, pp. 7-11, 1995, in Chinese.

[34] S. Han and B. Feeny, "Application of proper orthogonal decomposition to structural vibration analysis," Mechanical Systems and Signal Processing, vol. 17, no. 5, pp. 989-1001, 2003. 


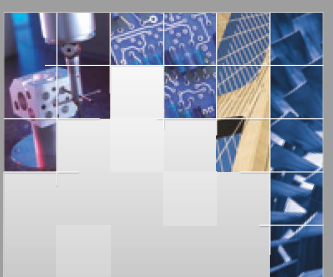

\section{Enfincering}
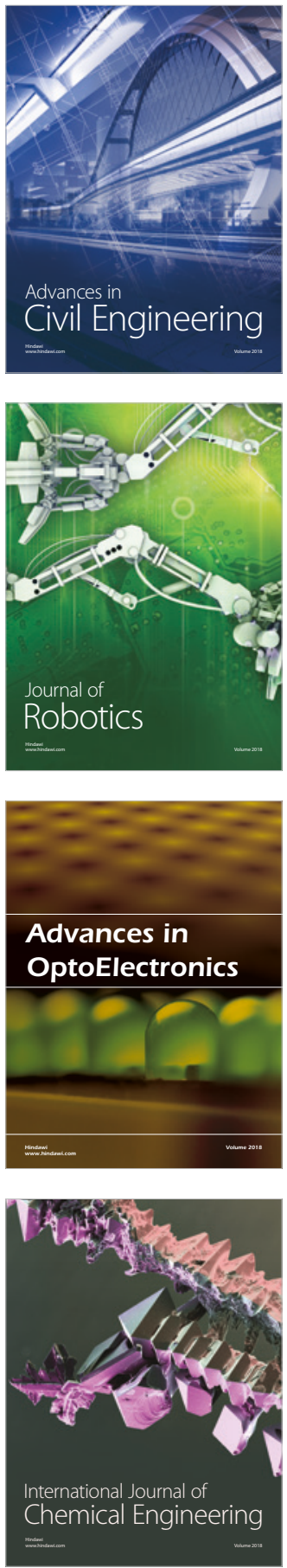

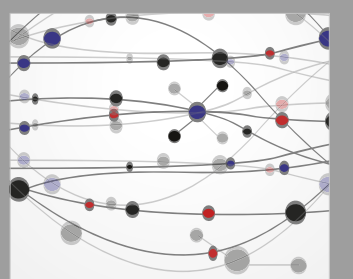

\section{Rotating \\ Machinery}

The Scientific World Journal

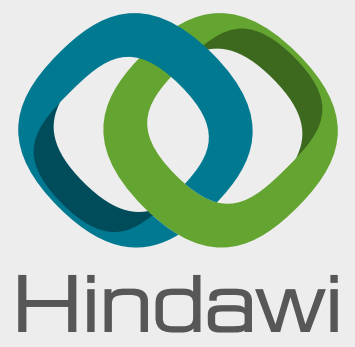

Submit your manuscripts at

www.hindawi.com
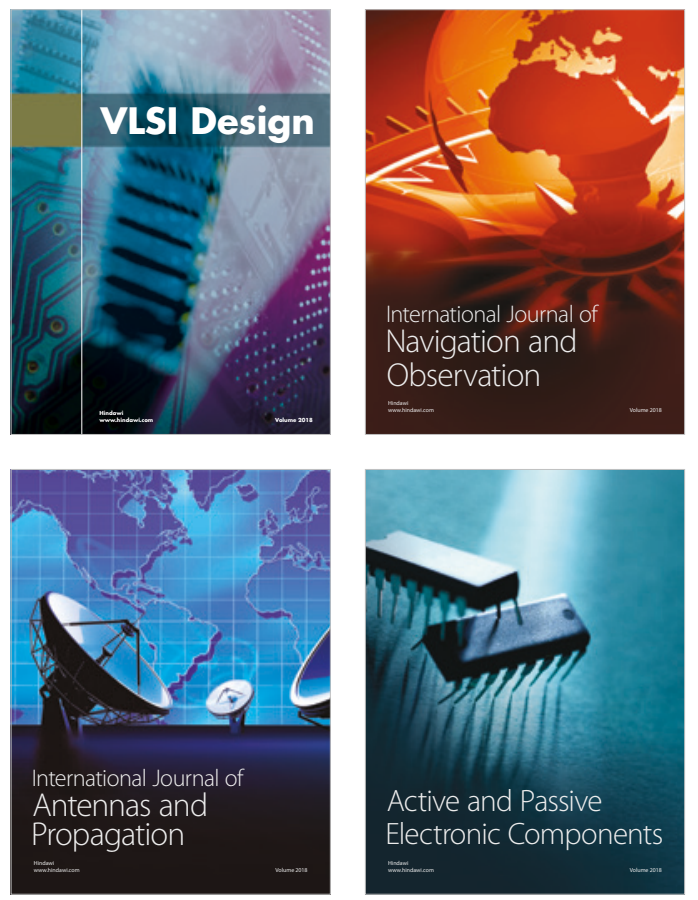
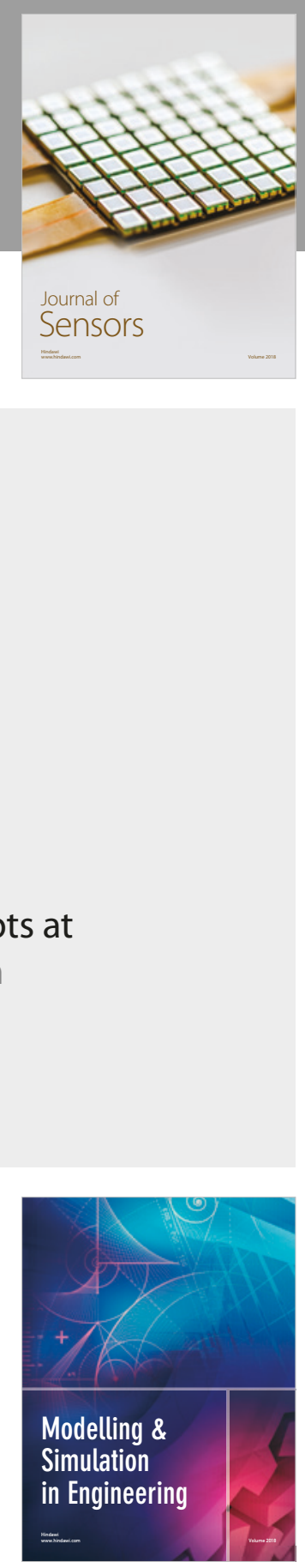

\section{Advances \\ Multimedia}
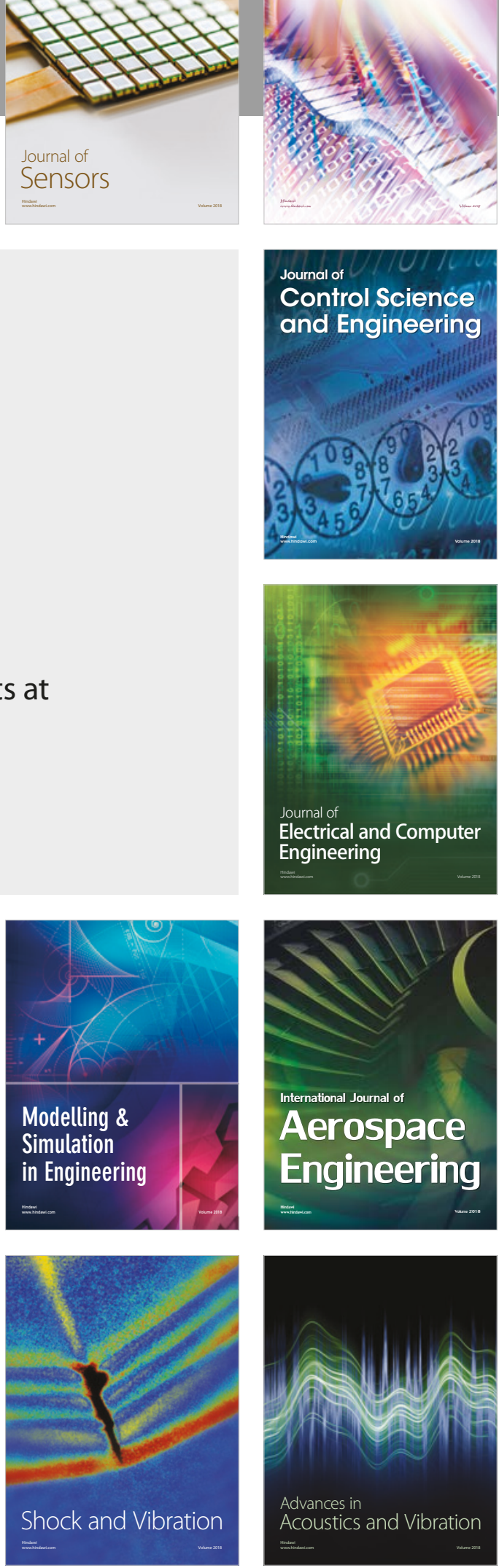